\title{
Injury-induced Plasticity of Spinal Reflex Activity: NK1 Neurokinin Receptor Activation and Enhanced A- and C-Fiber Mediated Responses in the Rat Spinal Cord in vitro
}

\author{
S. W. N. Thompson, A. Dray, and L. Urban \\ Sandoz Institute for Medical Research, London WC1E 6BN, United Kingdom
}

A- and C-fiber evoked ventral root potential (VRP) responses have been examined in isolated spinal cord preparations maintained in vitro that were taken from young rats in which behavioral hyperalgesia (thermal and mechanical) was induced following UV irradiation of one hindpaw. Evoked VRPs were compared with those in naive untreated animals. The duration of both the A- and C-fiber evoked VRP was significantly increased in UV-treated animals. The amplitude of the summated VRP evoked by repeated low-frequency (1.0-5.0 Hz) C-fiber stimulation, a measure of windup, was significantly greater in UV-treated animals. In UV-treated animals, repeated low-frequency $(1.0-5.0 \mathrm{~Hz})$ stimulation of A-fiber inputs to the spinal cord also evoked a significant summated VRP, which was not observed in spinal cords from untreated animals.

In naive animals the prolonged VRP evoked following single shock $\mathrm{C}$-fiber stimulation was significantly antagonized by the NMDA receptor antagonist D-AP5 and the NK2 receptor antagonist MEN,10376 but not by the NK1 receptor antagonists CP-96,345 or RP,67580. Summated VRPs evoked by repeated $\mathrm{C}$-fiber stimulation in naive animals were significantly antagonized only by D-AP5. In hyperalgesic animals the prolonged VRP evoked by $\mathrm{C}$-fiber stimulation was significantly reduced by NK1, NK2, and NMDA antagonists. The summated VRP was also significantly reduced by these antagonists. In both untreated and UV-irradiated animals the single shock evoked A-fiber ventral root response was significantly antagonized only by D-AP5. However, the summated VRP evoked by repeated A-fiber stimulation in UVtreated animals was also significantly reduced by NMDA, NK1, and NK2 receptor antagonists.

The present study has demonstrated enhanced A- and C-fiber evoked responses in the rat spinal cord in vitro following induction of a peripheral injury by UV irradiation and which was associated with behavioral hyperalgesia to thermal and mechanical stimuli. Under this condition, repetitive stimulation of A-fiber primary afferents was capable of producing an enhancement of spinal excitability similar to that evoked by $C$-fibers in normal animals. Furthermore, we have observed the expression of an NK1 receptor component to

\footnotetext{
Received July 1, 1993; revised Nov. 12, 1993; accepted Nov. 30, 1993.

We thank Dr. C Maggi for the gift of MEN,10376, Dr. V. Fardin for the gift of RP,67580, Dr. J. Dempster, Strathclyde University, for the use of his data analysis software, and Mr. M. Shipley, University College, London, for statistical advice.

Correspondence should be addressed to S. W. N. Thompson, Sandoz Institute for Medical Research, 5 Gower Place, London WCIE 6BN, UK.

Copyright (C) 1994 Society for Neuroscience $0270-6474 / 94 / 143672-16 \$ 05.00 / 0$
}

the C-fiber evoked response following the establishment of the peripheral injury. The enhanced ventral root responses and changes in receptor sensitivity may contribute to the phenomenon of central sensitization and may be directly related to the behavioral hyperalgesia observed. Moreover, these findings may be relevant to the mechanisms of enhanced central excitability that occur in clinical conditions of inflammatory hyperalgesia and neuropathic pain.

[Key words: spinal cord, plasticity, inflammation, pain, neurokinin, NK1, NK2, ventral root potential]

Peripheral tissue injury produces prolonged changes in the function of the nervous system. The hypersensitivity that results as a consequence of tissue injury and inflammation is due to an increased sensitivity of nociceptors that innervate the area of peripheral damage (peripheral sensitization; Bessou and Perl, 1969; Campbell et al., 1979; LaMotte et al., 1982) and to changes in the excitability of neurons within the spinal cord (central sensitization; Woolf, 1983; Treede et al., 1992). The induction of central sensitization is critically dependent upon the activation of nociceptive afferent fiber inputs (Wall and Woolf, 1984; Woolf and Wall, 1986) and has been observed following brief electrical stimulation of high-threshold afferent fibers (Cook et al., 1987; Woolf and King, 1990), the application of chemical irritants to human and animal skin (Hoheisel and Mense, 1987; Simone et al., 1989; Dougherty and Willis, 1992; LaMotte et al., 1992) and following peripheral inflammation (Schaible et al., 1987; Hylden et al., 1989).

A unique property of those primary afferent fibers responsible for the induction of central sensitization is their ability to evoke prolonged postsynaptic potentials in spinal cord neurons (Price et al., 1971; Urban and Randic, 1984; Yoshimura and Jessel, 1989; Thompson et al., 1990). These long-duration excitatory postsynaptic potentials (EPSPs) undergo pronounced temporal summation following low-frequency repetitive stimulation (Thompson et al., 1990) that results in a cumulative membrane depolarization and prolonged afterdischarge (Thompson et al., 1990; Sivilotti et al., 1993) and that underlies the phenomenon of "windup" (Mendell, 1966; Thompson et al., 1993b). Using a technique similar to that of Luscher et al. (1979) for recording postsynaptic population potentials, these long-duration EPSPs may also be recorded extracellularly as a prolonged ventral root potential (VRP) from in vitro spinal cord preparations (Akagi et al., 1985; Evans, 1986; Thompson et al., 1992). These prolonged VRPs also exhibit pronounced temporal summation following repeated high-intensity electrical stimulation of an ipsilateral dorsal root (Thompson et al., 1992, 1993a). This closely 
mimics the temporal summation of EPSPs and windup recorded intracellularly from spinal cord neurons in vivo and in vitro (Price et al., 1971; Woolf and King, 1989; Thompson et al., 1990).

Previous studies have implicated the involvement of the NMDA class of excitatory amino acid (EAA) receptor in the generation of slow synaptic potentials, windup, and injury-induced sensitization in the spinal cord (Davies and Lodge, 1987; Dickenson and Sullivan, 1987; Gerber and Randic, 1989a; Schneider and Perl, 1989; Thompson et al., 1990; Yoshimura and Jessel, 1990; Woolf and Thompson, 1991; Coderre and Melzack, 1992). In addition to the release of EAA transmitters, C-fiber activation uniquely results in the release of neuropeptides (Go and Yaksh, 1987) that are contained within the same afferent terminals in the superficial spinal cord (Battaglia and Rustioni, 1988). The neurokinins substance P (SP) and neurokinin A (NKA) are present along with distinct receptors within the mammalian spinal cord that mediate their biological effects (Hökfelt et al., 1975; Ogawa et al., 1985). These receptors have been designated NK1 and NK2, with SP and NKA as their preferred endogenous ligands (see Maggi et al., 1993, for review). Substantial evidence has now accumulated that suggests a role for neurokinins in nociceptive sensory function and in particular in the mediation of central sensitization (Xu et al., 1991, 1992a,b). Thus, SP produces slow postsynaptic depolarizations in dorsal horn neurons (Urban and Randic, 1984; Randic et al., 1988). Neurokinin antagonists strongly suppress slow synaptic transmission (Urban and Randic, 1984; Randic et al., 1988; DeKoninck and Henry, 1991; Nagy et al., 1993), prevent the development of windup (Kellstein et al., 1990, Xu et al., 1992b), and attenuate the flexor reflex facilitation evoked by either electrical nerve stimulation or exogenously applied neurokinins $(\mathrm{Xu}$ et al., 1992b). Studies performed with in vitro spinal cord preparations have shown that neurokinin antagonists also attenuate the extracellularly recorded VRP evoked by small-caliber afferent fiber stimulation (Yanagisawa et al., 1982; Otsuka and Yanagisawa, 1988; Nussbaumer et al., 1989; Woodley and Kendig, 1991; Thompson et al., 1993a) and under certain circumstances attenuate the temporal summation of these potentials that leads to windup (Thompson et al., 1993a). In previous studies, differing roles for the activation of the NK1 and NK2 classes of neurokinin receptors were suggested. This was dependent upon modality, intensity, and duration of afferent input (Thompson et al., 1993a). The present study has further assessed the role of the NK1 and NK2 receptor activation in the generation of the prolonged VRP and windup. The contribution of different neurokinin receptors has been assessed in naive rats and in animals in which hyperalgesia had been established following brief UV irradiation of one hindpaw. Characterized as a model of prolonged hyperalgesia, this model has been shown to display features of hyperalgesia that may be sustained by both peripheral and central mechanisms (Perkins et al., 1993).

\section{Materials and Methods}

UV irradiation of the hindpaw. Hyperalgesia was induced in neonatal rat pups using the method previously described in detail for adult rats (Perkins et al., 1993). The glabrous surface of the left hindpaw of neonatal Sprague-Dawley rat pups (8-12 d old) was exposed to a cold UVA light source $\left(365 \mathrm{~nm}, 69 \mathrm{nW} / \mathrm{cm}^{2}\right)$ for $90 \mathrm{sec}$. This exposure was repeated $18 \mathrm{hr}$ later.

Behavioral testing. On each of the following days 1-6 (designated UV1-UV6) separate groups of four rat pups were placed into a transparent, Pcrspex box. The withdrawal latency of cach hindpaw to a focused radiant heat beam was measured in a pseudorandom manner; hence, animals were not tested in sequence and no individual animal had both paws tested sequentially. A 2 min interval was kept between tests. The paw temperature was measured with a thermistor and plotted as a function of time following stimulus presentation, from which an estimate of heat threshold for paw withdrawal could bc obtaincd. The mechanical threshold of the hindpaws was measured in separate groups of four animals from UV1 to UV5 using a modified Randall-Sellito paw pressure test. The plantar surface of the left hindpaw of a lightly restrained rat pup was placed upon a flat Perspex stage. The pressure on a second flat Perspex probe placed on top of the foot was gradually increased. The end point was measured as the pressure at which the paw was withdrawn from between the probes. Each group of four animals was tested only once.

In naive rat pups, reflex thresholds are known to increase with age. Hence, neonatal animals have much lower mechanical thresholds than adult rats (Fitzgerald et al., 1987). Rat pups were therefore exposed to the UV radiation at a suitable postnatal age (postnatal days 8-12; PND 8-12) so that all animals were within $4 \mathrm{~d}$ of age when the behavioral testing was carried out (PND 12-15). Control groups of rat pups werc tested alongside UV-treated animals and consisted of age-matched untreated animals (naive rat pups).

In vitro preparation and recording. The extent of the thermal and mechanical hyperalgesia observed following the second UV treatment was maximal between days 1 and 3 , with no significant difference in the degree of hyperalgesia obtained between these two times. In the present study, therefore, spinal cords from animals on the first day following the final UV irradiation (UV1) were further analyzed for physiological and pharmacological studies and taken as representative for this period of the hyperalgesia. Spinal cords from UV4, UV5, UV6, or hemisected cords contralateral to the UV lesion were not tested in this study. Hemisected spinal cords ipsilateral to the UV lesion were prepared from UV1 treated and naive animals using identical surgical procedures. Animals were decply ancsthetized following Enflurane inhalation and the spinal column containing all thoracic and sacral segments was rapidly removed and submerged in oxygenated Krebs solution (in mM: $\mathrm{NaCl}, 138.0 ; \mathrm{KCl}, 1.35 ; \mathrm{NaHCO}_{3}, 21.0 ; \mathrm{NaH}_{2} \mathrm{PO}_{4}, 0.58$; $\mathrm{MgCl}_{2}, 1.16 ; \mathrm{CaCl}_{2}, 1.26$; glucose, 10.0$)$ at $4^{\circ} \mathrm{C}$. The spinal cord was subsequently removed from the spinal column and hemisected in Krebs' solution at $4^{\circ} \mathrm{C}$, constantly oxygenated and perfused. The left-hand side hemisected spinal cord was routinely used and extended from $\mathrm{T} 6 / 7$ to the cauda equina. A recovery period of at least $2 \mathrm{hr}$ was left between removal of the cord and recording. A major portion of the primary afferent fibers innervating the plantar surface of the rat hindpaw have cell bodies distributed in the L5 dorsal root ganglion (Molander and Grant, 1986). Responses were therefore recorded from the L5 ventral root following stimulation of the ipsilateral L5 dorsal root in all experiments (L5 DR-VRP). Spinal cords were placed in a Perspex recording chamber $(1.0 \mathrm{ml}$ approximate volume $)$ and superfused at $5 \mathrm{ml} / \mathrm{min}$ with the same modified oxygenated Krebs solution at room temperature (18$22^{\circ} \mathrm{C}$ ). The $\mathrm{L} 5$ dorsal root was stimulated via a glass suction electrode with constant current stimuli at a distance of approximately $15 \mathrm{~mm}$ from the dorsal root entry zone. Initial experiments were carried out to determine the electrical thresholds for dorsal root afferent fiber activation. In these experiments the dorsal root, dorsal root ganglia, and peripheral nerve were taken from animals of the same age and receiving the same treatments as for the spinal cord experiments. In four experiments the compound action potential (CAP) was recorded from the sciatic nerve following single shock electrical stimulation of the dorsal root via the suction electrode. The following stimulation intensities were used throughout the present study: $5 \mathrm{~V}$ for $20 \mu \mathrm{sec}$ represented $2 \times \mathrm{Th}$ (twice threshold) intensity for the activation of a single rapidly conducting CAP (see Fig. 3). In addition to the fast-conducting CAP, a discrete long-latency CAP, which reflected the activation of slowly conducting unmyelinated and thin myelinated afferent fibers, was evoked by $50 \mathrm{~V}, 200 \mu \mathrm{sec}$ pulses. This stimulus intensity also represented $2 \times \mathrm{Th}$ for the slowly conducting afferent fiber wave. A closely fitting glass suction electrode placed over the L5 ventral root in close contact to the ventral horn was used to record the ventral root potential (VRP) evoked by dorsal root stimulation. Stable DC recordings of the evoked VRPs could be recorded for several hours by this method. CAPs and VRPs were amplified and digitized using an Axon instruments Labmaster TL-1 DMA interface and recorded onto hard disk using SC.AN software (J. Dempster, Strathclyde University).

Drugs and solutions. All drugs were made up from frozen aliquots dissolved to their final concentration in the Krebs solution prior to application and perfused to the recording chamber as indicated. The following compounds were used: the selective NK1 receptor antagonists 
Figure 1. Typical VRP evoked following single shock stimulation of highthreshold dorsal root afferents is shown in the presence and absencc of D-AP5. Three distinct components of the VRP are indicated: (1) the early wave, also present following low-threshold afferent fiber activation, and which is resistant to the NMDA receptor antagonist D-AP5; (2) the slow component, which is only present following high-threshold activation and is that portion of the response which is highly dependent upon activation of the NMDA class of EAA receptor; and (3) the prolonged wave, a very long duration high-threshold evoked response, whose peak amplitude occurs at approximately $2.0 \mathrm{sec}$ and which is resistant to D-AP5.

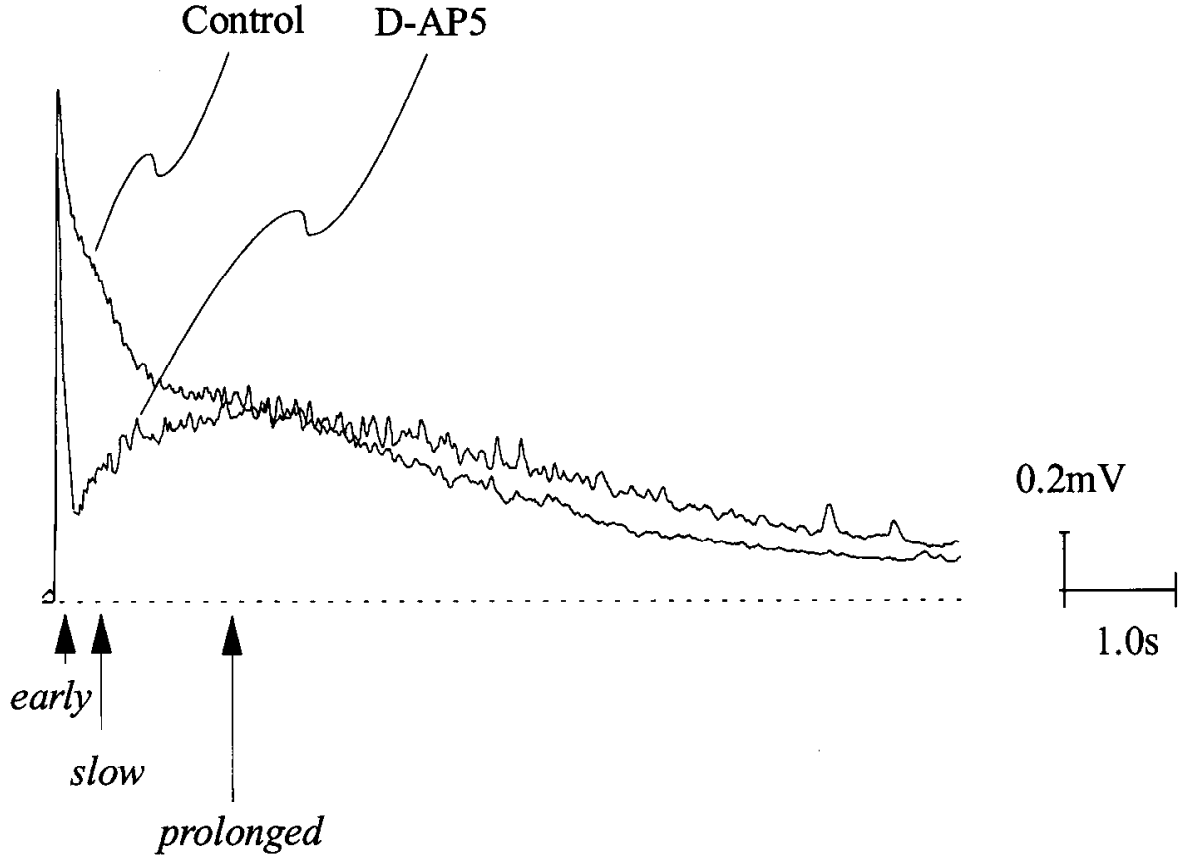

RP,67580 and its inactive enantiomer RP,68651 [(2-(1-imino-2-(2 methoxy phenyl) ethyl)-7,7 diphenyl-4 perhydroisoindolone-(3aR,7aR)], a gift from Rhone Poulenc Rorer Chemicals, was dissolved in $0.1 \mathrm{~N}$ hydrochloric acid and stored in frozen aliquots, and racemic CP-96,345 [cis-2-(diphenylmethyl)- $N$-[(2-methoxyphenyl)-methyl]-1-azabicyclo[2.2.2.]octan-3-amine] was synthesized at Sandoz AG Basle. MEN, 10376 [Tyr, D-Trp, Lys-NKA (4-10)] was a gift from Menarini Pharmaceuticals, Florence, Italy. D-AP5 (D-2-amino-5-phosphonopentanoic acid) was obtained from Sigma. Antagonist concentrations used were as follows: CP-96,345, $500 \mathrm{nM}$; RP, 67580 and RP,68651, $100 \mathrm{nM}$; MEN, 10376, $100 \mathrm{~nm}$; D-AP5, $20 \mathrm{~m}$. We have previously demonstrated that racemic CP-96,345 acts as a competitive antagonist against substance $\mathrm{P}$ methyl ester (SPOMe)-induced responses in the neonatal rat spinal cord preparation with an apparent affinity coefficient $\left(\mathrm{p} K_{B}=7.25\right)$ similar to that reported elsewhere (Beresford et al., 1991). The concentration of RP, 67580 used in the present experiments (100 nM) was in excess of the $\mathrm{IC}_{50}(16.1 \mathrm{nM})$ previously calculated for its action against SPOMe-induced responses in the rat spinal cord preparation (Thompson et al., 1993a). The concentration of MEN, 10376 (100 nM) used in the present study was the same as that previously shown to abolish completcly and specifically NKA (300 nM)-cvoked depolarizing responses in deep dorsal horn neurons in the neonatal rat spinal cord in vitro (Nagy et al., 1993). Drugs were applied by bath perfusion to the spinal cord. MEN, 10376 was applied 40 min prior to and during testing in all cases and its effects were completely reversed following $30 \mathrm{~min}$ wash. CP-96,345, RP,67580, and RP,68651 were applied 20 min prior to testing in all cases and effects were reversed following 20 min wash.

Characteristics of the VRP. Previous studies (Thompson et al., 1992, 1993a) have demonstrated several components to the VRP following electrical stimulation of the ipsilateral dorsal root that may be distinguished by their response threshold, response latency, and pharmacological profile. Briefly, the early component of the VRP is a shortduration A-fiber evoked wave, resistant to NMDA receptor antagonists but sensitive to the non-NMDA receptor antagonists. Stimulus intensities that recruit slowly conducting C-fibers evoke a very long duration VRP consisting of the early NMDA-resistant component also observed with the low-intensity stimulation, a longer-latency slow NMDA-sensitive component, and a further very long duration prolonged component (Fig. 1). This prolonged component is NMDA resistant, has its peak amplitude at a latency of approximately $2.0 \mathrm{sec}$, and is only present at stimulus strengths sufficient to activate slowly conducting unmyelinated and thin myelinated afferent fibers (Thompson et al., 1992). In our present experiments the following parameters of the VRP were measured. (1) Following low-intensity dorsal root stimulation, the peak amplitude and the integrated VRP area were measured between 0 and
$2.0 \mathrm{sec}$ latency. This period encompassed the whole of the low-threshold evoked response. (2) Following high-intensity stimulation the prolonged VRP area was measured between 0 and $4.0 \mathrm{sec}$ latency. This area contained the whole of the NMDA-dependent slow VRP component and the majority of the NMDA-independent prolonged response. The prolonged VRP amplitude was measured at a latency of $2.0 \mathrm{sec}$, the peak latency of this wave (see Fig. 1). (3) The early and prolonged VRP duration following either low- or high-threshold afferent fiber stimulation was measured as the time to return to baseline potential. Statistical evaluation was carried out using methods in Snederor and Cochran (1978). One-way analysis of variance (ANOVA) followed by Dunnett's multiple comparison test or a Student's $t$ test assuming equal variance was carried out as appropriate. All values in the text are expressed as mean \pm SEM

\section{Results}

Thermal and mechanical hyperalgesia following $U V$ irradiation

On the first day following UV treatment (UV1) a marked erythema was present in the treated paw without evidence of tissue damage. Inflammation of the ipsilateral paw was present by day 2 and persisted throughout UV3-UV4. Typically, blistering of the glabrous skin with some weeping was apparent by UV5. Throughout this period no sign of inflammation or injury was present on the contralateral untreated hindpaw. The animals did not appear to be in distress over this time period and continued to feed and groom and develop at a normal rate compared to litter mates.

Figure 2 shows the time course of the mean paw withdrawal latencies to a thermal stimulus and mean paw pressure tolerated for groups of UV-treated animals following the final UV treatment in comparison to age-matched naive rat pups. Thermal hyperalgesia, recorded as a significant drop in the paw withdrawal latency from a radiant heat beam, was present in both the ipsilateral and contralateral hindpaws throughout the period of testing. On UV1 the withdrawal latency of the ipsilateral hindpaw was significantly reduced to $5.3 \pm 0.48 \mathrm{sec}(p<0.01$, $t$ test; $n=11$ ). This represented $40.8 \pm 3.9 \%$ of control value $(13.2 \pm 0.5 \mathrm{sec})$. On UV3 the withdrawal latency had further 

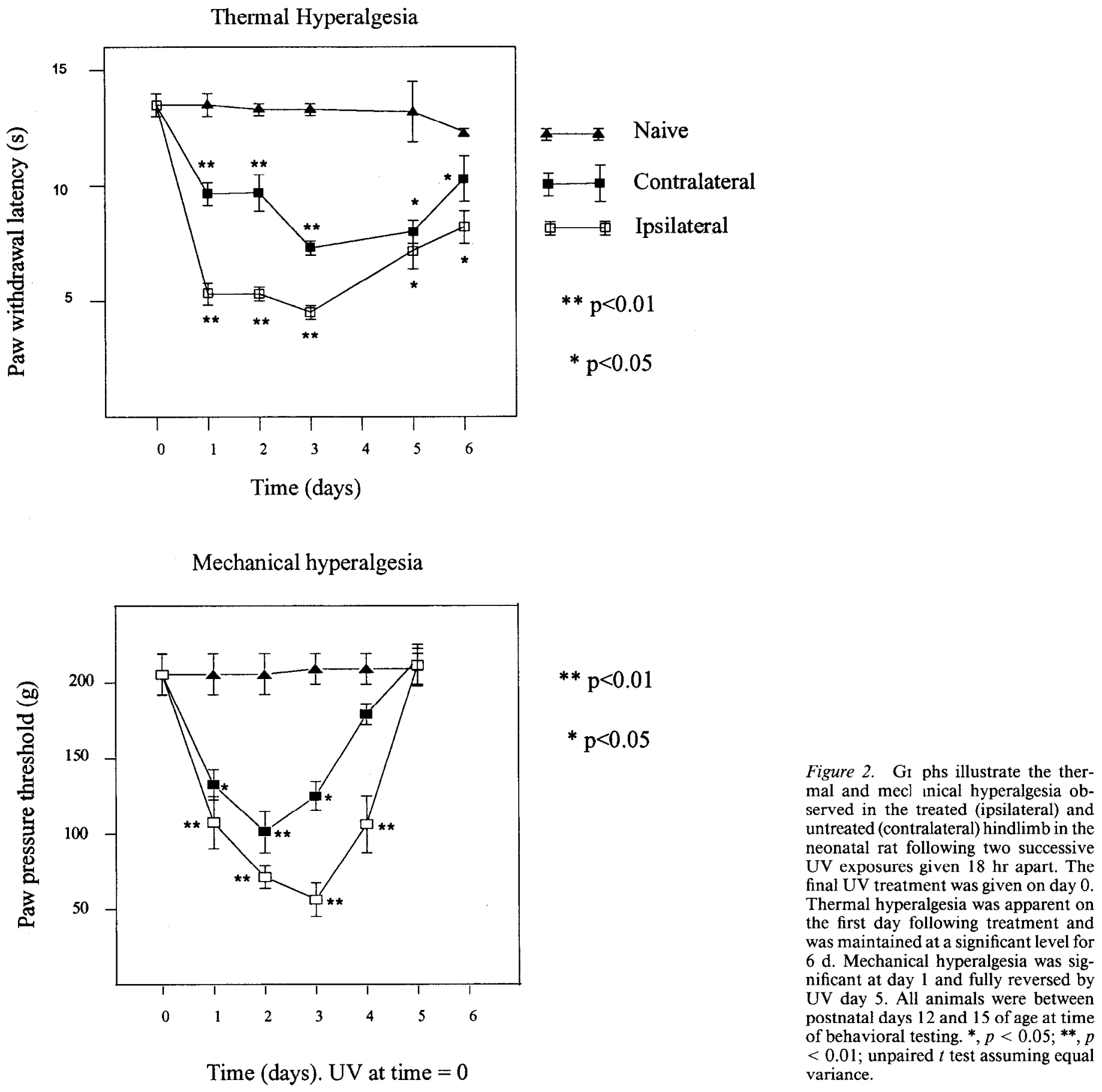

fallen to $4.5 \pm 0.29 \sec (n=4 ; 33.7 \pm 2.2 \%$ of control). This corresponded to a heat threshold for paw withdrawal of approximately $37^{\circ} \mathrm{C}$ compared to approximately $46^{\circ} \mathrm{C}$ in naive animals. Partial recovery of the paw withdrawal latency was apparent on UV5. Full recovery of the ipsilateral paw withdrawal latency had not taken place by UV6, when the testing ended. A significant contralateral thermal hyperalgesia was also present that was maximal on UV3 (withdrawal latency $7.25 \pm$ $0.29 \mathrm{sec}, 54.2 \pm 2.1 \%$ of control; $p<0.01, t$ test; $n=4$ ). This corresponded to a heat threshold for paw withdrawal of approximately $40.0^{\circ} \mathrm{C}$. The contralateral thermal hyperalgesia also persisted to UV6 $(p<0.01)$.
Mechanical hypersensitivity was also observed as a significant decrease in the mean paw pressure threshold in both ipsilateral and contralateral hindpaws. On UV1 the weight tolerated by the ipsilateral hindpaw was $108.7 \pm 17.37 \mathrm{gm}$; this represented $52.6 \pm 8.4 \%$ of control weight tolerated by naive animals (206.4 $\pm 13.8 \mathrm{gm} ; p<0.01, t$ test; $n=11$ ). By UV3 the weight was $57.5 \pm 11.2 \mathrm{gm}(n=4 ; 27.3 \pm 5.3 \%)$ compared to a control weight of $210.0 \pm 10.0 \mathrm{gm}(n=4)$. Contralateral values for UV1 and UV3 were $133.7 \pm 9.8 \mathrm{gm}(n=11 ; 67.6 \pm 5.0 \%)$ and $126.2 \pm 9.4 \mathrm{gm}(n=4 ; 53.7 \pm 4.0 \%)$, respectively. Both ipsilateral and contralateral paw pressure tolerance was not significantly different from naive scores by UV5. 
Figure 3. Comparison of VRP evoked following high- and low-threshold afferent fiber stimulation in untreated and UV-treated animals. $A$, Low-intensity $(5 \mathrm{~V}, 20 \mu \mathrm{sec})$ single shock electrical stimulation of the dorsal root evokes a single fast-conducting compound action potential (CAP) on the peripheral nerve (inset). A significant difference in VRP duration between naive and UVtreated preparations is present. Arrowhead shows the time to return to baseline in naive preparation. The arrow gives the equivalent point for UV-treated preparation. $B$, High-intensity $(50 \mathrm{~V}$, $200 \mu \mathrm{sec}$ ) single shock electrical stimulation of the dorsal root evoked an additional slowly conducting CAP ( $a r$ row in inset). The corresponding prolonged VRP is shown from UV-treated and untreated (naive) animals. A significant difference was also apparent in the durations of the prolonged VRP. The time to return to basclinc of the prolonged VRP in the naive preparation is arrowed. The equivalent response from the UV-treated preparation extended beyond the sweep period.
$\mathbf{A}$
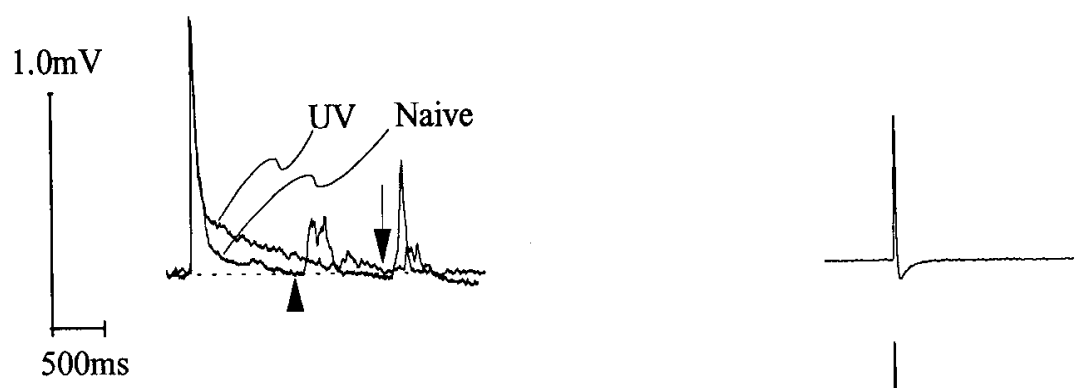

$0.2 \mathrm{mV}$

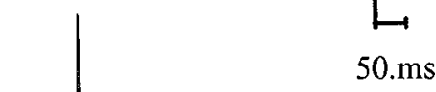

B

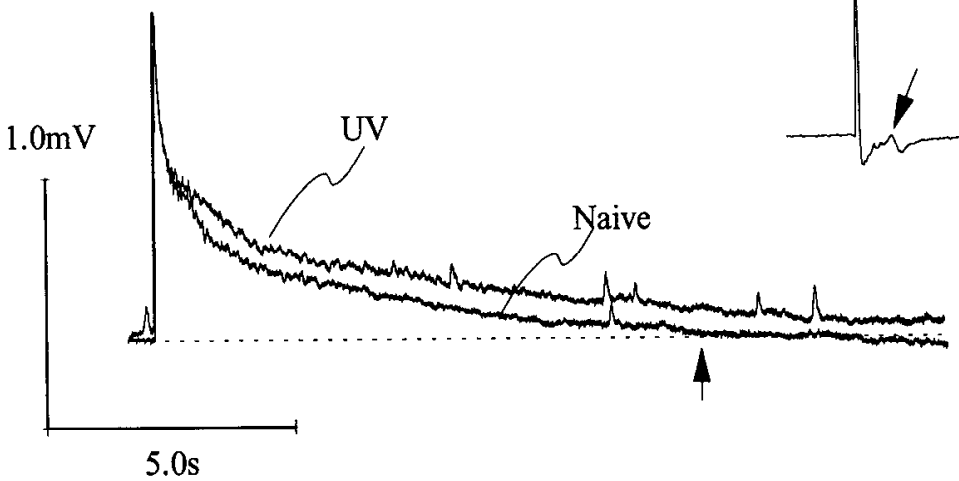

\section{Characterization of VRP: single shock evoked VRP}

Hemisected spinal cords were prepared from a total of $11 \mathrm{UV} 1$ treated animals taken immediately following behavioral testing. Hemisected spinal cords (left-hand sides) from 13 age-matched naive rat pups were used in control experiments.

In preliminary experiments the CAP was measured from the sciatic nerve following single shock electrical stimulation of the L5 dorsal root in both UV-treated and naive age matched rat pups. Low-intensity electrical stimulation ( $5 \mathrm{~V}, 20 \mu \mathrm{sec}$ ) evoked a short-latency CAP (Fig. $3 A$, inset). The conduction velocity $(\mathrm{CV})$ of this wave recorded from the sciatic nerve was between 3.52 and $5.25 \mathrm{~m} \mathrm{sec}^{-1}$. No significant difference was observed in the threshold or $\mathrm{CV}$ of the low-intensity CAP between naive and UV-treated animals. Figure 3 shows the corresponding VRPs recorded in response to a single shock low-intensity stimulus to the L5 DR in naive and UV1 treated animals. No significant difference was measured between the VRP amplitude or integrated area (measured between 0 and 2.0 sec following stimulus artifact) between naive and UV-treated animals. The duration

Table 1. Comparison of the A- and C-fiber cvoked VRP in naive and UV-treated animals

\begin{tabular}{llc} 
& Naive animals & $\begin{array}{c}\text { UV-treated } \\
\text { animals }\end{array}$ \\
\hline $\begin{array}{l}\text { Low-threshold afferent fiber evoked } \\
\text { Early VRP area }(\mathrm{mV} \cdot \mathrm{sec})\end{array}$ & $0.20 \pm 0.04$ & $0.29 \pm 0.04$ \\
Early VRP peak amplitude (mV) & $(10)$ & $(11)$ \\
Farly VRP duration (sec) & $0.54 \pm 0.08$ & $0.73 \pm 0.10$ \\
High-threshold afferent fiber evoked & $(10)$ & $(11)$ \\
Prolonged VRP area (mV·sec) & $1.64 \pm 0.31$ & $\mathbf{4 . 2 8} \pm \mathbf{0 . 6 *}$ \\
& $(9)$ & $(11)$ \\
Prolonged VRP amplitude at $2.0 \mathrm{sec}(\mathrm{mV})$ & $1.01 \pm 0.13$ & $1.38 \pm 0.21$ \\
& $(13)$ & $(11)$ \\
Prolonged VRP duration $(\mathrm{sec})$ & $0.22 \pm 0.03$ & $0.32 \pm 0.05$ \\
& $(13)$ & $(11)$ \\
& $9.60 \pm 0.78$ & $\mathbf{1 5 . 6 2} \pm \mathbf{1 . 5 6 *}$
\end{tabular}

Mcan valucs and SEs for the arca, amplitude, and duration of the low- and high-threshold afferent evoked ventral root responses in naive animals are given and compared to those values recorded in UV1 animals. Numbers of preparations are in parentheses. The early VRP response consisted of the short-duration A-fiber evoked wave measured between 0 and $2 \mathrm{sec}$. The prolonged VRP response is the very long duration A-plus C-fiber evoked response. Those values shown in boldface and marked with an asterisk indicate a significant difference between measured parameters.

* Significant difference from naive value $p<0.05 t$ test. 
Naive



$1.0 \mathrm{~Hz}, 5 \mathrm{~V} 20 \mathrm{us}$

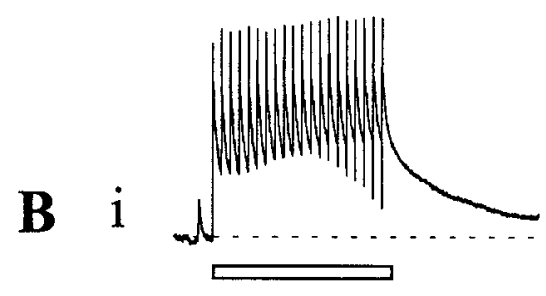

$1.0 \mathrm{~Hz}, 50 \mathrm{~V} 200 \mathrm{us}$



$1.0 \mathrm{~Hz}, 5 \mathrm{~V} 20 \mathrm{us}$

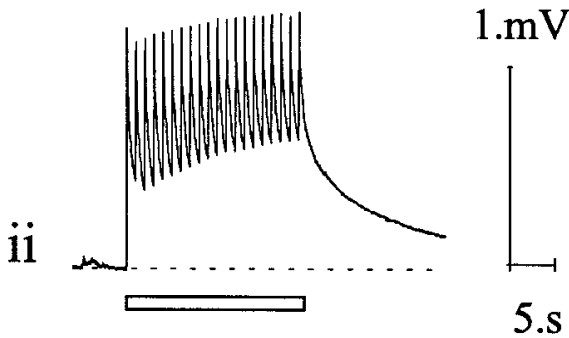

$1.0 \mathrm{~Hz}, 50 \mathrm{~V} 200 \mathrm{us}$
Figure 4. The summated VRP evoked following low-frequency repetitive stimulation. $A$, Repetitive $(1.0 \mathrm{~Hz})$ stimulation of low-threshold afferent fibers was given for the period indicated by the horizontal bar. Ai, Spinal cords from untreated animals were unable to sustain any summated depolarization at low stimulus intensities. Aii, In UVtreated animals a substantial and suslained depolarization was evoked following identical low-threshold afferent fiber stimulation as that given in $A i . B i$, Repetitive low-frequency $(1.0 \mathrm{~Hz})$ stimulation of high-threshold afferent fibers delivered during the period indicated by the horizontal bar evoked a maintained summated depolarization in untreated animals. Bii, Identical stimulation in UV-treated animals evoked a summated VRP significantly greater in amplitude. $C$, Graph comparing the VRP amplitude evoked in treated and untreated animals following repetilive low- and high-threshold afferent fiber stimulation. The summated VRP amplitude evoked by lowthreshold (LT) afferent tiber stimulation in UV-treated animals (solid bars) was significantly greater than in naive animals (open bars) at all stimulation frequencies ( 1.0 and $5.0 \mathrm{~Hz}$ shown). The high-threshold $(H T)$ afferent fiber evoked summated VRP (solid bars) was also significantly greater in UV-treated animals at all stimulation frequencies. ${ }^{*}, p<0.05$, unpaired $t$ test. of the low-threshold afferent fiber evoked VRP was significantly greater however, in UV-treated rat pups than in naive animals $(p<0.01$; Table 1).

High-intensity electrical stimulation of the L5 DR (50 V, 200 $\mu \mathrm{sec})$ in addition to the rapidly conducting CAP also recruited a slowly conducting CAP in the sciatic nerve $\left(0.27-0.32 \mathrm{msec}^{-1}\right.$; Fig. $3 B$, inset arrow). The threshold and $\mathrm{CV}$ of this slowly conducting CAP were similar in both naive and UV-treated animals and presumably represented conduction in unmyelinated and thin myelinated afferent fibers. The corresponding ventral root response is shown in Figure $3 B$. Typically, a very long duration prolonged VRP was recorded from the L5 ventral root. The difference measured in the integrated area of the prolonged VRP or the VRP amplitude between naive and UV-treated animals was not significant. However, the VRP duration was significantly greater in UV-treated animals than in naive rat pups ( $p$ $<0.05, t$ test; Table 1).

\section{Summated VRP evoked by repetitive stimulation}

High-threshold afferent stimulation. A low-frequency (1.0-5.0 $\mathrm{Hz}$ ), high-intensity dorsal root stimulation for $20.0 \mathrm{sec}$ evoked a temporal summation of the prolonged VRP that results in a summated VRP (Thompson et al., 1992, 1993a). The final amplitude of the summated VRP evoked following 20 sec stimulation in UVl animals $(0.65 \pm 0.1 \mathrm{mV}, n=11$ at $1.0 \mathrm{~Hz} ; 0.94$ $\pm 0.13 \mathrm{mV}, n=11$ at $5.0 \mathrm{~Hz}$ ) was significantly different from 
Naive
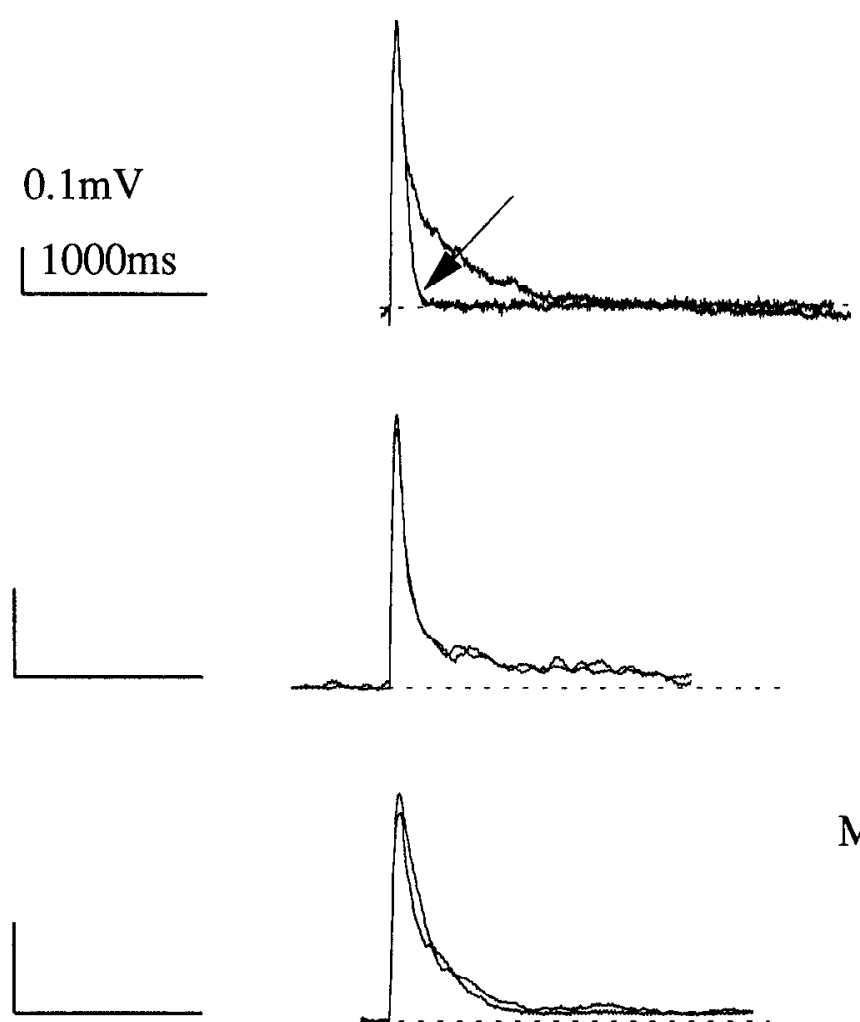

$\mathrm{RP}, 67580$

\section{D-AP5}
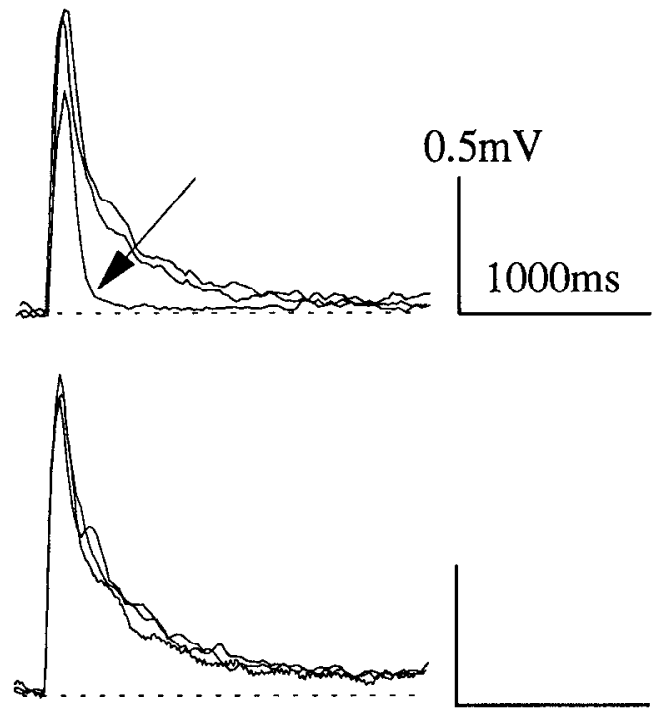

MEN,10376

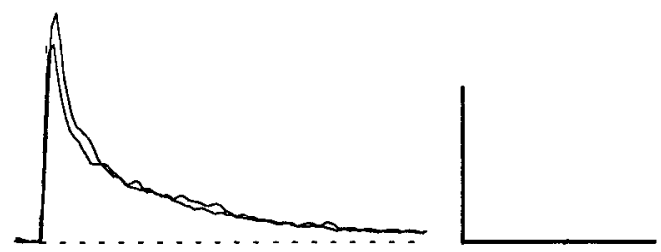

Figure 5. The effects of NMDA and neurokinin receptor antagonists are shown upon the single shock A-fiber evoked VRP in both UV-treated and untreated (naive) animals. Upper traces, The monosynaptic, short-latency VRP remains unaffected following 20 min bath application of the NMDA receptor antagonist D-AP5 $(20 \mu \mathrm{M})$ in both UV1 and naive animals. Only the short-duration residual polysynaptic activity was affected by the D-AP5. Middle and lower traces show that neither the nonpeptide NK1 receptor antagonists RP,67580 (100 nM) applied for 20 min, nor the peptide NK2 receptor antagonist MEN, $10376(100 \mathrm{nM})$ applied for $40 \mathrm{~min}$ had any significant effect upon the VRP in either UV1 or naive animals. Each panel shows control, wash, and drug responses (arrowed when different from control). All traces are an average of four responses.

that cvoked at comparable frequencics of stimulation in naive animals $(0.36 \pm 0.05 \mathrm{mV}, n=10$ at $1.0 \mathrm{~Hz} ; 0.61 \pm 0.07 \mathrm{mV}$, $n=10$ at $5.0 \mathrm{~Hz} ; p<0.05, t$ test; Fig. 4).

Low-threshold repetitive afferent fiber stimulation. In naive animals, repetitive stimulation at low stimulus intensities, which activates only the rapidly conducting A-fiber wave on the CAP, did not evoke a significant summated VRP at any frequency of stimulation tested up to $10.0 \mathrm{~Hz}$. This reflects the inability of low-threshold afferent fiber input under normal conditions to evoke windup in the spinal cord. In UV1 animals, however, a substantial summated VRP was evoked following low-threshold afferent fiber stimulation at both $1.0 \mathrm{~Hz}(0.17 \pm 0.03 \mathrm{mV}, n=$ 8 ) and $5.0 \mathrm{~Hz}(0.41 \pm 0.08 \mathrm{mV}, n=8$ ) (Fig. $4 A, C)$ that was significantly different from that measured in naive animals ( $p$ $<0.05, t$ test). The summated VRP evoked by $5.0 \mathrm{~Hz}$ repetitive A fiber stimulation in UV-treated animals gave an equivalent

Table 2. The effect of NMDA and neurokinin receptor antagonists upon the A-fiber evoked response in naive and UV-treated animals

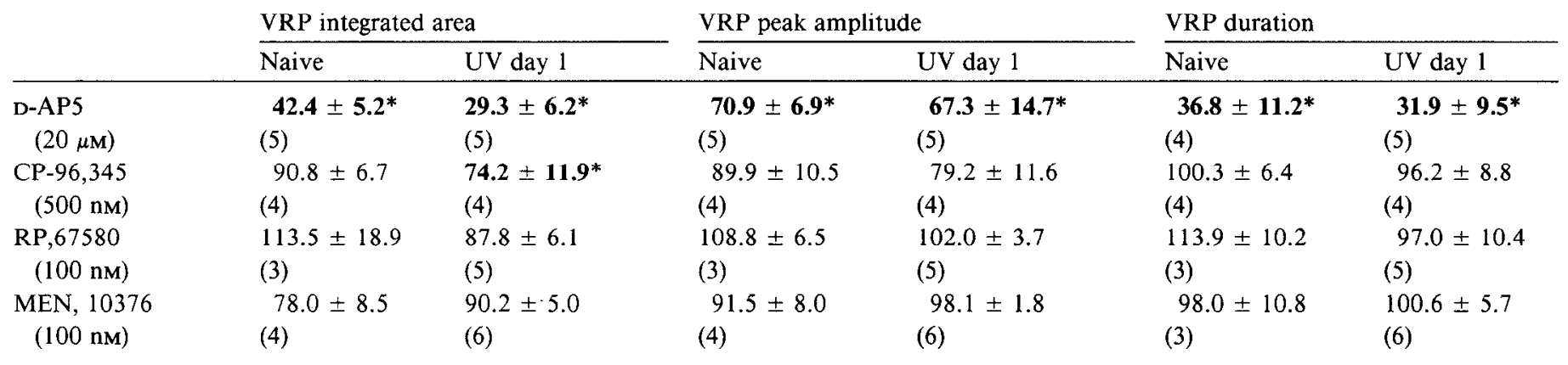



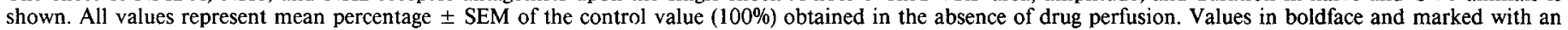
asterisk show significant difference from control value $(p<0.05$, ANOVA). Numbers in parentheses represent number of preparations. 

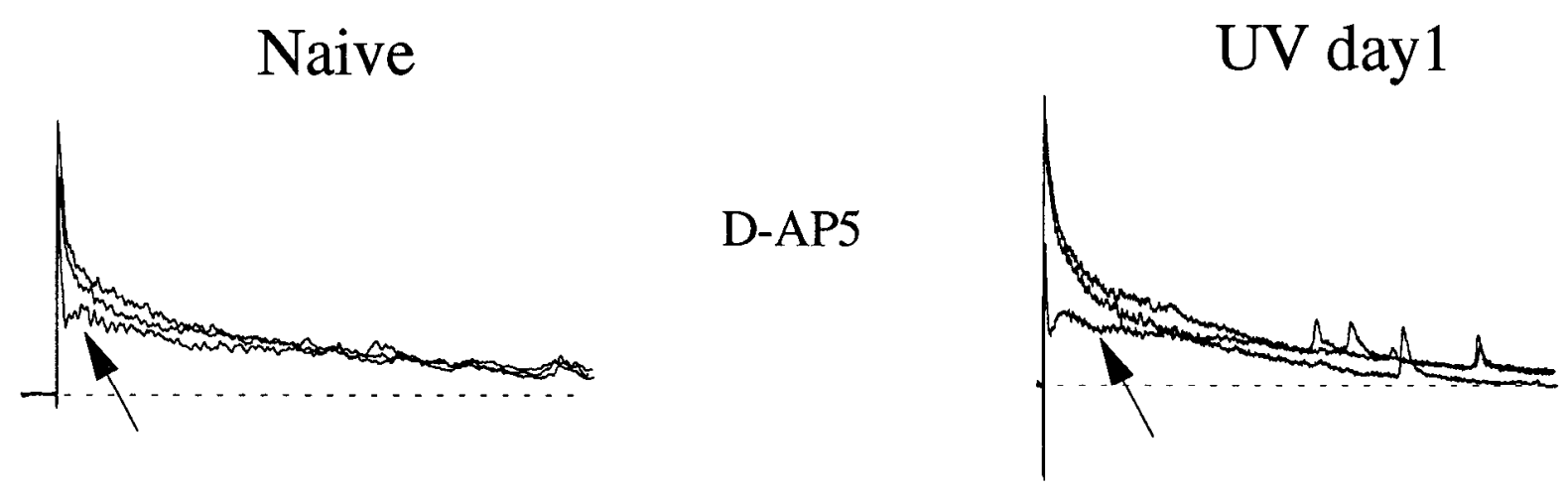

\section{$0.5 \mathrm{mV}$



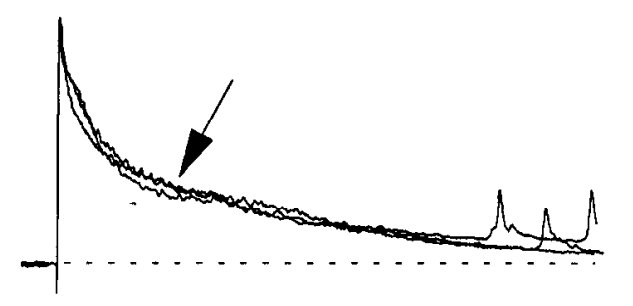
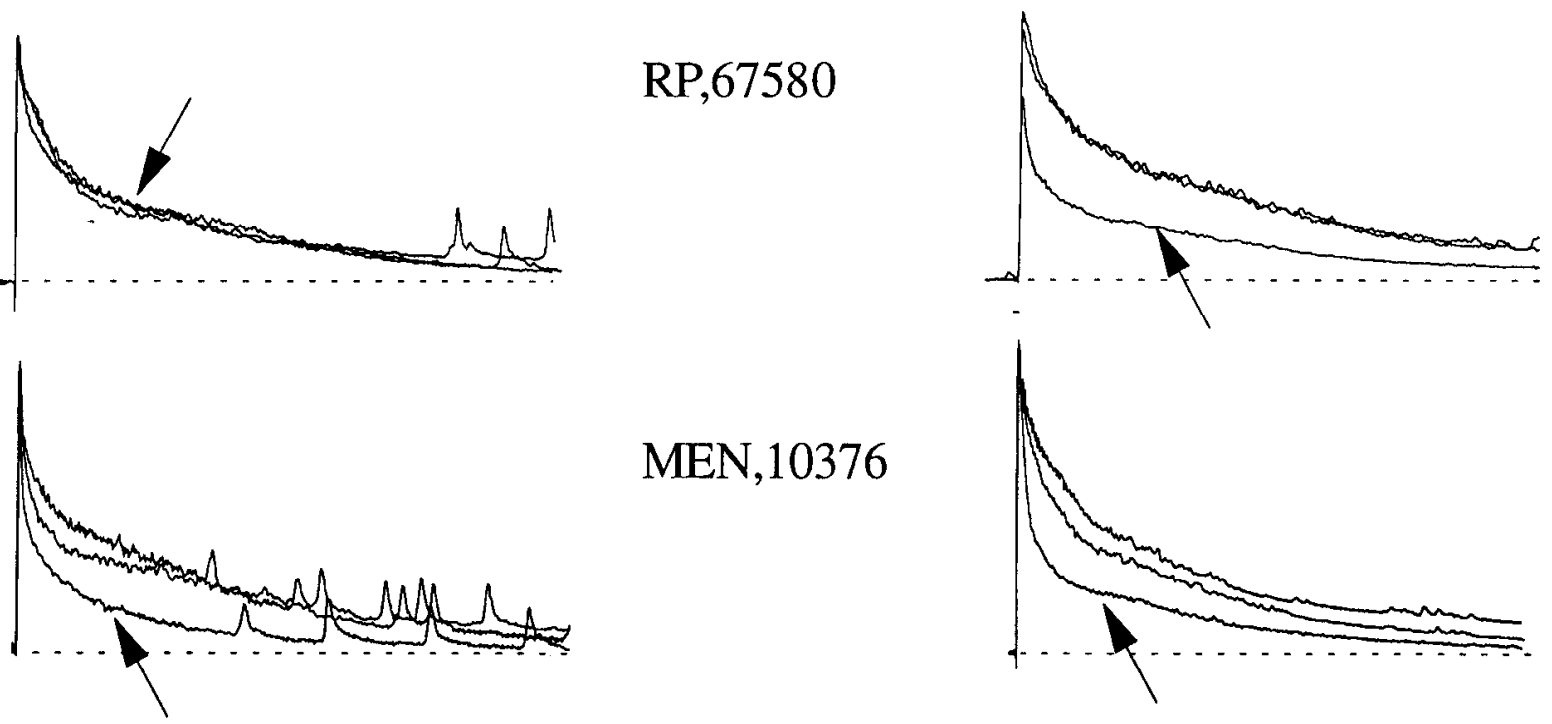

Figure 6. The effect of NMDA and neurokinin receptor antagonists upon the prolonged VRP evoked following single shock high-intensity electrical stimulation of the dorsal root in both UV-treated and naive animals. Upper traces, D-AP5 $(20 \mu \mathrm{M})$ significantly reduced the prolonged VRP area in both UV-treated and untreated animals. The effect in both is confined to the early portion (0-2 sec) of the response (indicated by the arrow). Middle traces, The nonpeptide NK1 antagonist RP,67580 (100 nM) applied for 20 min did not effect the prolonged VRP in naive animals. Following UV treatment the effect of this antagonist is highly significant (arrows). Lower traces, The effect of the peptide NK2 antagonist MEN,10376 (100 nM) is significant in both naive and UV-treated animals (arrows). All panels show control, wash, and drug traces (arrows). All traces are an average of four responses.

mean amplitude of depolarization to that evoked following 1.0 $\mathrm{Hz}$ high-threshold afferent fiber stimulation in naive animals (Fig. 4C).

\section{Effect of NMDA and neurokinin receptor antagonists upon the single shock evoked VRP}

A-fiber evoked response. The effects of the NMDA and neurokinin receptor antagonists upon the early VRP following single shock low-threshold afferent fiber stimulation are shown in Figure 5 and summarized in Table 2 . D-AP5 $(20 \mu \mathrm{M})$ significantly reduced the area, peak amplitude, and duration of the evoked early VRP compared to control in both naive and UV1 animals. No significant difference was present between the effect of D-AP5 in naive or UV1 treated animals. The nonpeptide NK 1 receptor antagonists RP, $67580(100 \mathrm{nM})$ and the peptide NK2 receptor antagonist MEN,10376 (100 nM) had no detectable effect upon any parameter of the A-fiber evoked early VRP in either naive or UV-treated animals. The NK1 receptor antagonist CP-96,345 $(500 \mathrm{nM})$ significantly reduced $(74.2 \pm 11.9 \%$ of control) only the area of the A-fiber VRP in UV1-treated animals. RP,68651 $(100 \mathrm{nM})$ had no significant effect upon any measured parameter.

High-threshold afferent evoked response. Figure 6 shows the effect of the neurokinin and NMDA receptor antagonists upon the prolonged VRP evoked following single shock stimulation of high-threshold dorsal root afferent fibers. In naive animals the prolonged VRP area was significantly reduced $(p<0.05$, ANOVA) following bath application of D-AP5. This reduction was restricted to the early portion of the response $(0-2 \mathrm{sec}$ latency). The mean VRP amplitude mcasurcd at latency of 2.0 sec and VRP duration were unaffected by the NMDA antagonist. In naive animals no significant differences from control values were observed in any measured parameter of the prolonged VRP following $20 \mathrm{~min}$ bath application of either the active or inactive NK1 antagonists CP-96,345 (500 nM), RP,67580 (100 nM), or RP,68651 (100 nM). Following superfusion with MEN,10376 $(100 \mathrm{nM})$, however, the prolonged VRP area and amplitude were significantly reduced $(p<0.05$, ANOVA; see Table 3$)$. The VRP duration, however, was not significantly effected. These results confirm that under normal circumstances NMDA and NK2 receptor activation but not NK1 receptor activation contribute to the different but overlapping components of the prolonged VRP.

Figure 6 also shows the effects of NMDA and neurokinin antagonists upon the prolonged VRP evoked in UV1 animals. 
Table 3. The effect of NMDA and neurokinin receptor antagonists upon the C-fiber evoked response in naive and UV-treated animals

\begin{tabular}{|c|c|c|c|c|c|c|}
\hline & \multicolumn{2}{|c|}{ VRP integrated area } & \multicolumn{2}{|c|}{ VRP amplitude at $2.0 \mathrm{sec}$} & \multicolumn{2}{|c|}{ VRP duration } \\
\hline & Naive & UV day 1 & Naive & UV day 1 & Naive & UV day 1 \\
\hline $\begin{array}{l}\text { D-AP5 } \\
\qquad(20 \mu \mathrm{M})\end{array}$ & $\begin{array}{l}\mathbf{8 1 . 3} \pm 5.6^{*} \\
(8)\end{array}$ & $\begin{array}{l}70.0 \pm 6.5^{*} \\
(5)\end{array}$ & $\begin{array}{l}92.3 \pm 6.4 \\
(8)\end{array}$ & $\begin{array}{l}84.3 \pm 9.1 \\
(5)\end{array}$ & $\begin{array}{l}97.7 \pm 5.3 \\
(6)\end{array}$ & $\begin{array}{l}98.9 \pm 4.3 \\
(3)\end{array}$ \\
\hline $\begin{array}{r}\mathrm{CP}-96,345 \\
(500 \mathrm{nM})\end{array}$ & $\begin{array}{l}93.4 \pm 8.4 \\
(6)\end{array}$ & $\begin{array}{l}61.7 \pm 8.2 * \dagger \\
\text { (4) }\end{array}$ & $\begin{array}{l}93.0 \pm 11.8 \\
(6)\end{array}$ & $\begin{array}{l}64.9 \pm 5.3^{*} \\
(4)\end{array}$ & $\begin{array}{l}95.8 \pm 4.5 \\
(4)\end{array}$ & $\begin{array}{l}86.7 \pm 7.1 \\
\text { (3) }\end{array}$ \\
\hline $\begin{array}{l}\mathrm{RP}, 67580 \\
(100 \mathrm{nM})\end{array}$ & $\begin{array}{l}104.6 \pm 2.2 \\
\text { (3) }\end{array}$ & $\begin{array}{l}72.6 \pm 4.6 * \dagger \\
(5)\end{array}$ & $\begin{array}{l}110.8 \pm 7.7 \\
(3)\end{array}$ & $\begin{array}{l}68.8 \pm 4.8 * \dagger \\
(5)\end{array}$ & $\begin{array}{l}107.4 \pm 0.8 \\
(3)\end{array}$ & $\begin{array}{l}\mathbf{8 1 . 1} \pm \mathbf{5 . 3} * \dagger \\
(5)\end{array}$ \\
\hline $\begin{array}{c}\text { MEN, } 10376 \\
(100 \mathrm{~nm})\end{array}$ & $\begin{array}{l}70.4 \pm 10.2^{*} \\
\text { (4) }\end{array}$ & $\begin{array}{l}70.8 \pm 6.8^{*} \\
(6)\end{array}$ & $\begin{array}{l}65.9 \pm 15.5^{*} \\
(4)\end{array}$ & $\begin{array}{l}70.6 \pm 5.8^{*} \\
(6)\end{array}$ & $\begin{array}{l}83.5 \pm 9.3 \\
(4)\end{array}$ & $\begin{array}{l}97.4 \pm 9.7 \\
(5)\end{array}$ \\
\hline
\end{tabular}






naive value ( $p<0.05$, ANOVA). Values in parentheses represent number of preparations.

Bath application of $20 \mu \mathrm{M}$ D-AP5 significantly reduced the prolonged VRP area ( $p<0.05$, ANOVA). This reduction was confined to the early portion of the response and was not significantly different from the effect of D-AP5 in naive animals (Table 3). The prolonged VRP amplitude and duration were similarly unaffected by $\mathrm{D}$-AP5 in UV1 treated animals as in naive animals. In contrast to naive animals, however, the NK1 receptor antagonists CP-96,345 and RP,67580 both produced a significant reduction in the integrated area and amplitude of the prolonged VRP $(p<0.05$, ANOVA). In particular, the effect of RP, 67580 upon the area and amplitude of the prolonged VRP in UVI treated animals was significantly different from its effect upon the same parameters in naive animals $(p<0.05$, ANOVA; see Table 3 ). The prolonged VRP duration was also significantly reduced in UV1 animals in the presence of RP, $67580(p<0.05$, ANOVA), an effect significantly different from that in naive animals ( $p<0.05$ ANOVA). The inactive enantiomer RP,68651 did not have any significant effect upon any parameter. The effect of the NK2 receptor antagonist MEN,10376 (100 nM) upon all three parameters of the prolonged VRP in UV 1 treated animals was not significantly different to its effect in naive animals (see Table 3).

The effect of NMDA and neurokinin receptor antagonists upon the summated depolarization evoked by repetitive stimulation

Low-threshold afferent fiber repetitive stimulation. In naive animals, repetitive low-threshold afferent fiber stimulation did not produce any sustainable summated depolarization, so the effects of NMDA or neurokinin receptor antagonists were not tested. The effect of these antagonists upon the summated VRP evoked following repetitive low-intensity stimulation in UV1 animals is shown in Figure 7. A significant reduction $(p<0.05$ in each case, ANOVA) in the amplitude of the summated VRP was produced by D-AP5 ( $42.8 \pm 6.0 \%$ of control, $n=5)$, RP, 67580 $(82.1 \pm 6.2 \%$ of control, $n=6)$, CP-96,345 (62.0 $\pm 7.4 \%$ of control, $n=6$ ), and MEN,10376 (71.6 $\pm 8.2 \%$ of control, $n=$ 11).

High-threshold afferent fiber repetitive stimulation. In naive animals the amplitude of the summated VRP evoked following repetitive high-threshold afferent fiber stimulation was significantly reduced following bath application of D-AP5 (68.0 \pm $2.6 \%$ of control, $n=39 ; p<0.05$, ANOVA). No significant effect of any NK1 or NK2 receptor antagonist was observed upon the amplitude of this potential (Fig. 8B). In UV1 animals the amplitude of the summated VRP was also significantly reduced from control in the presence of D-AP5 $(52.8 \pm 6.0 \%$ of control, $n=5 ; p<0.05$, ANOVA) and this effect was significantly greater than that observed in naive animals $(p<0.05$ ANOVA). In UVI animals the summated VRP amplitude was significantly reduced following bath application of RP,67580 $(89.9 \pm 2.4 \%$ of control, $n=10)$, CP-96,345 (70.2 $\pm 3.8 \%$ of control, $n=12)$, and MEN, $10376(87.8 \pm 3.4 \%$ of control, $n$ $=13$ ) (see Fig. 8). The effects of RP,67580 and CP-96,345 in UV1 animals were significantly different from their effects in naive animals. There was no significant effect of RP,68651 upon the amplitude of the summated VRP.

\section{Discussion}

These experiments have demonstrated that a prolonged hypersensitivity of the hindlimb flexor reflex may be produced in neonatal rat pups following a unilateral peripheral injury. Using the novel approach of recording extracellularly from spinal cords maintained in vitro prepared from hyperalgesic animals, we have observed a marked plasticity of spinal cord function associated with the behavioral hypersensitivity.

Extrapolation of the present results to fully adult animals may be complicated because of the relative immaturity of the animals used. However, we have used rat pups toward the end of the second postnatal week, the time at which the neurochemical and anatomical appearance of C-fiber terminals in the dorsa! horn of the spinal cord approaches that of the adult (Fitzgerald and Gibson, 1984), the physiological function of C-fibers is virtually established (Fitzgerald, 1985) and the appearance of the cutaneous afferent volley closely resembles that of the adult (Fitzgerald, 1985). At this age, however, the ficxion reflex threshold is still lower than in the adult (Fitzgerald et al., 1987) but is beyond the time (PND 0-7) whereby innocuous as well as noxious peripheral stimuli may evoke the flexion reflex (Fitzgerald et al., 1987). By using age-matched untreated rat pups as controls, however, we have demonstrated that the hindlimb flexion reflex shows a reliable and prolonged sensitization in response to injury.

UV irradiation has been used previously to induce acute sensitization of afferent fibers (Szolcsányi, 1987) and to produce acute inflammation of the hindpaw (Gillardon et al., 1991). Recently this model has also been shown to display features of both acute and prolonged hyperalgesia (Perkins et al., 1993). In the present study both thermal and mechanical hypersensitivity 
A

Control

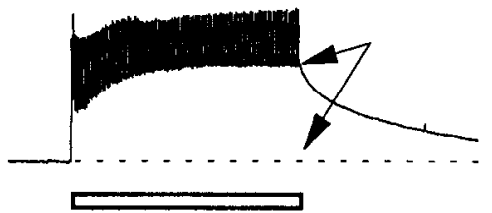

$5.0 \mathrm{~Hz}, 5 \mathrm{~V}, 20 \mathrm{us}$

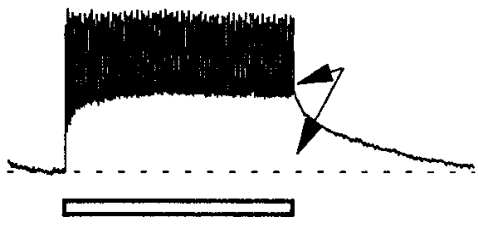

$1 . \mathrm{mV}$



5.5

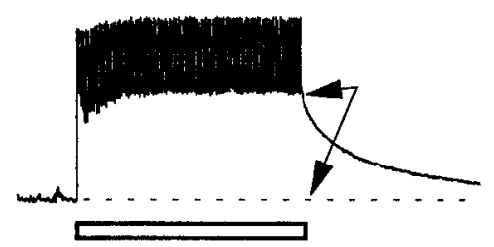

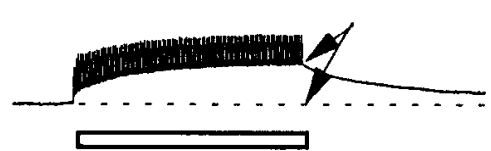

RP,67580

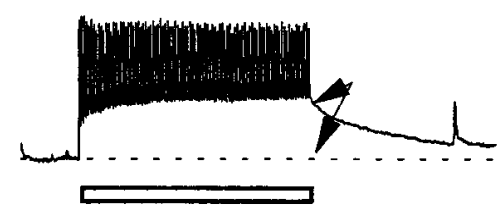

MEN,10376

D-AP5

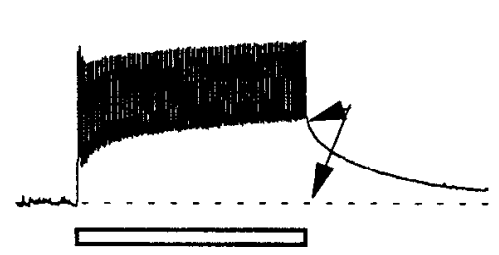

B



Figure 7. The effect of NMDA and neurokinin receptor antagonists upon the novel A-fiber evoked summated VRP in UV-treated animals. $A$, The effect of D-AP5 $(20 \mu \mathrm{M}), \mathrm{RP}, 67580(100$ $\mathrm{nM}$ ), and MEN, 10376 (100 nM) upon the amplitude of the summated VRP evoked following $5.0 \mathrm{~Hz}$ repetitive stimulation at low intensity $(5 \mathrm{~V}, 20$ $\mu \mathrm{sec}$ ) for $20 \mathrm{sec}$ at the time indicated by the horizontal bars in UV-treated animals is shown. Summated VRP amplitudes were measured between the $a r$. rows. All of the antagonists used had a significant effect upon the summated VRP amplitude. $B$, The graph shows the percentage change in VRP amplitude following drug application compared to control value in the absence of drug $(0 \%)$. All compounds produced a significant reduction in VRP amplitude $\left({ }^{*}, p<0.05\right.$, ANOVA); numbers of observations are in parentheses.

were reliably recorded in the ipsilateral treated hindpaw as well as in the contralateral untreated paw. The time course of the hypersensitivity in the contralateral paw mirrored that of the ipsilateral paw, and both returned to control levels faster than observed in the adult animals (Perkins et al., 1993). Contralat- eral hyperalgesia and reductions in contralateral flexor reflex thresholds have also been demonstrated in adult animals following a localized thermal injury to the hindpaw (Woolf, 1984). Cutaneous and deep tissue injury also produce an increase in the ipsilateral and contralateral flexion withdrawal reflex in re- 
Figure 8. The effect of NMDA and neurokinin receptor antagonists upon the C-fiber evoked summated VRP in naive and UV-treated animals. $A$, The effect of D-AP5 $(20 \mu \mathrm{M}), \mathrm{RP}, 67580(100$ nM), and MEN,10376 (100 nM) upon the summated VRP amplitude evoked following $1.0 \mathrm{~Hz}$ repetitive stimulation at high intensity $(50 \mathrm{~V}, 200 \mu \mathrm{sec})$ for 20 $\mathrm{sec}$ at the times indicated by the hori zontal bars. Example traces are shown only from UV-treated animals. Control, drug, and wash responses are shown. VRP amplitudes were measured between the arrowed points. In contrast to untreated animals all antagonists significantly reduced the summated VRP amplitude. $B$, Summary data for both naive and UV-treated animals. The percentage change in summated VRP amplitude is shown measured relative to control $(100 \% \cong 0)$ following drug application in both UVtreated (solid bars) and untreated (open bars) animals. D-AP5 $(20 \mu \mathrm{M})$ produced a significant reduction from control amplitude in both UV-treated and untreated animals $\left(^{*}, p<0.05\right.$, ANOVA) with a significantly greater effect in UVtreated animals $(\#, p<0.05$, ANOVA). Neither NK1 antagonist (CP-96,345 or $\mathrm{RP}, 67580$ ) produced any significant effect from control in untreated animals. However, in UV-treated animals both antagonists produced a significant reduction in summated VRP amplitude (*, $p<0.05$, ANOVA) from control. The NK2 antagonist MEN,10376 (100 nM) did not produce any significant effect in untreated animals but a small significant depression in UV-treated animals $\left(^{*}, p<0.05\right.$, ANOVA). Number of observations is in parentheses.
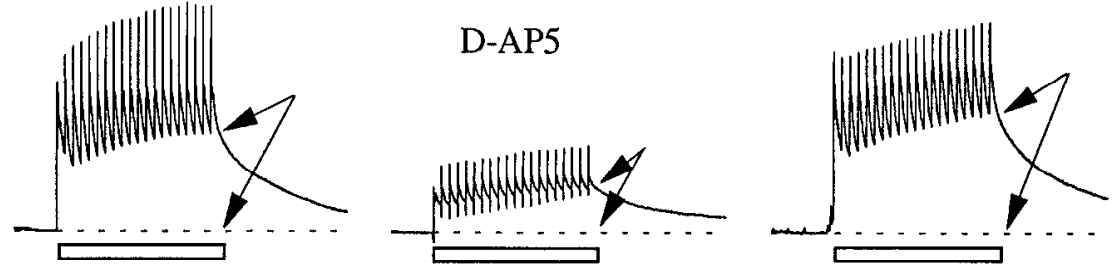

$1.0 \mathrm{~Hz}, 50 \mathrm{~V}, 200 \mathrm{us}$
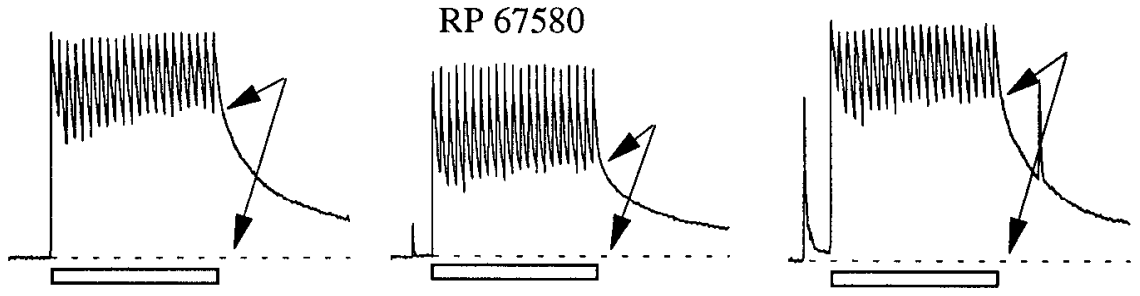

$1 . \mathrm{mV}$
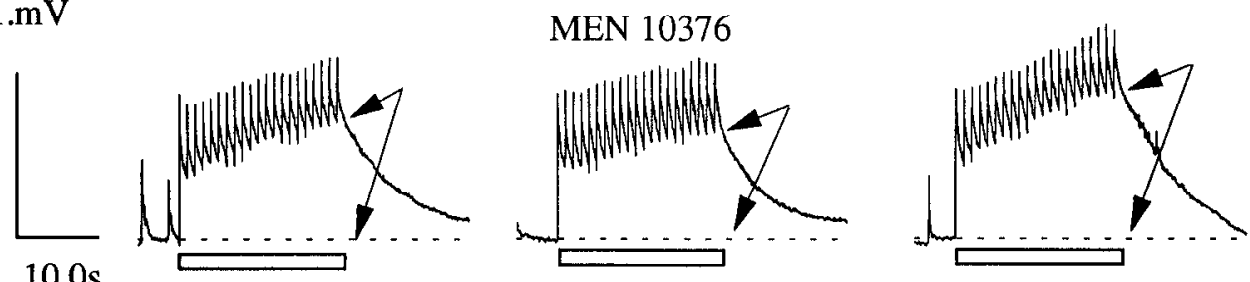

B

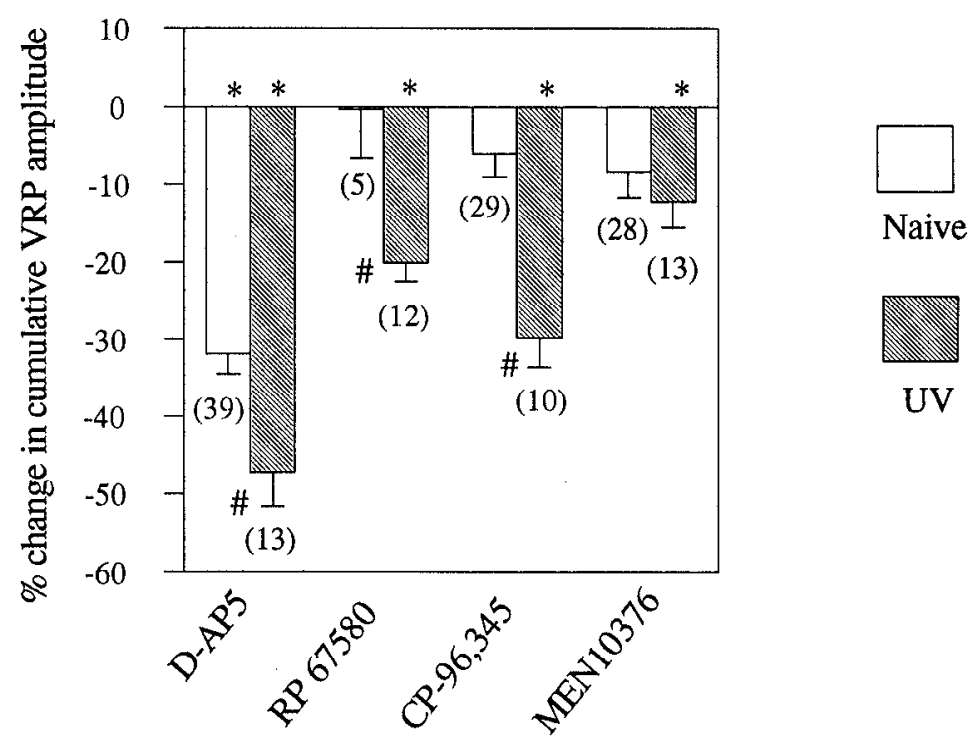

sponse to noxious pinch of the hindpaw (Woolf, 1983; Woolf and McMahon, 1985). The characteristics of the contralateral reflex were not examined in our present experiments in vitro but require further careful analysis.

No change was detected in the threshold or conduction velocity of either the A or C wave compound action potential evoked following electrical stimulation of the dorsal root. There is no evidence to suggest that inflammation-induced sensitization of afferent terminals may influence the electrical threshold of the acutely sectioned proximal axon. However, UV irradiation of the adult rat hindpaw induced an increase in spontaneous activity in high-threshold afferent fibers (Szolcsányi, 1987; Andreev and Dray, 1992). In a recent study where the responses of dorsal horn cells were recorded following UV-induced injury, dorsal rhizotomy partially reduced spontaneous activity in spinal cord neurons presumably by removing the source of this peripherally generated activity (Urban et al., 1993). In the present study dorsal rhizotomy was performed in both UV-treated 
and naive spinal cords. Following clcctrical stimulation of the sectioned dorsal roots, therefore, it is likely that the evoked afferent volley is similar in both UV-treated and naive isolated spinal cord preparations.

\section{Changes in the ventral root responses evoked following afferent} fiber stimulation

The duration of both the A- and C-fiber evoked VRP was significantly enhanced in UV-treated animals when compared to naive animals. Several mechanisms may account for these observations. Peripheral tissue injury, inflammation, or nerve injury produces extensive alterations in the properties of spinal cord neurons. For example, the peripheral receptive fields of dorsal horn neurons increase in size following thermal or mechanical injury (McMahon and Wall, 1984; Laird and Cervero, 1989) or following the injection of chemical irritant substances into joints and skin (Calvino et al., 1987; Schaible et al., 1987; Hylden et al., 1989; Simone et al., 1989). These modifications in receptive field properties may also be mimicked by brief highintensity electrical nerve stimulation (Cook et al., 1987). The cutaneous receptive fields of flexor motoneurons also exhibit similar dynamic changes following injury or high-threshold electrical nerve stimulation (Woolf, 1983; Woolf and McMahon, 1985; Woolf and Wall, 1986). These changes are generally considered to be mediated by alterations in excitability within the spinal cord (see Treede et al., 1992, for review). Similar changes in receptive field properties were evoked by UV-induced inflammation of the hindpaw in the rat (Urban et al., 1993). In this case the spontaneous activity and responses of dorsal horn neurons to noxious thermal and mechanical stimuli were also significantly increased. Moreover, spontaneous and evoked activity was only partially reduced following dorsal rhizotomy, indicating that the increase in responsiveness was in part centrally mediated. In the present experiments enhanced afferent evoked ventral root responses were recorded in an isolated spinal cord maintained in vitro. This also suggests that centrally mediated excitability changes are responsible.

The summated VRP evoked by low-frequency repeated stimulation of high-threshold dorsal root afferents (Thompson et al., $1993 a, b)$ is considered to reflect the cumulative depolarization of membrane potential of ventral horn neurons. This is a complex phenomenon that has been described in detail elsewhere (Sivilotti et al., 1993) and underlies the phenomenon of windup, and may be used as an index of central sensitization within the spinal cord (Thompson et al., 1993b). The present experiments have shown that the final amplitude of this summated VRP was significantly enhanced following a peripheral inflammation. One of the most striking features, however, was the observation that following UV inflammation, repeated low-frequency stimulation of A-fiber afferents also evoked a summated VRP, comparable in amplitude to that evoked following C-fiber stimulation in control animals. Repetitive A-fiber inputs in naive animals never evoked any significant summated VRP. Indeed, repeated low-threshold inputs to motoneurons in the neonatal rat spinal cord in vitro may exhibit prolonged, frequency-dependent synaptic depression (Lev-Tov and Pinco, 1992). Prcvious experiments have shown that the cumulative depolarization of membrane potential of spinal cord cells, evoked following high-intensity repetitive electrical stimulation, was partially dependent upon the duration of the single shock evoked composite synaptic potential. The temporal summation of synaptic events was only assured when the postsynaptic depolarization exceeded the interstimulus interval in duration and consequently summated (Thompson et al., 1990). This mechanism, however, does not normally operate during repeated A-fiber stimulation since temporal summation of low-threshold evoked synaptic potentials did not occur even at high-rates of stimulation frequency (Thompson et al., 1990; Lev-Tov and Pinco, 1992). Of importance here, therefore, is the finding that the rate of rise of membrane depolarization following repetitive stimulation is a more accurate predictor of the final amplitude of the cumulative depolarization (Sivilotti et al., 1993). The duration of the A-fiber evoked VRPs, however, was sufficiently large following UVinduced inflammation to permit a substantial temporal summation following low-frequency stimulation. Of significance here is that both NK1 and NK2 receptor antagonists reduce the amplitude of the A-fiber evoked summated VRP. This suggests peptidergic containing polysynaptic dorsal horn circuits, normally responsible for relaying information from high-threshold nociceptors, may be accessed by A-fiber input following periphery injury or inflammation. A more detailed pharmacological analysis of the relative potencies of neurokinin antagonists against the low- and high-threshold afferent evoked responses may provide some insight into the mechanisms involved. Neuropeptides are known to be present within dorsal horn interneurons and may be detected following dorsal rhizotomy (Ogawa et al., 1985). Intracellular analysis of the organization of dorsal horn neuron receptive fields has demonstrated that nociceptive-specific dorsal horn neurons have a substantial subthreshold input from low-threshold afferent fibers (Woolf and King, 1989), and this may contribute to the dynamic changes in dorsal horn cells observed following injury. Thus, nociceptive specific neurons, which prior to the application of algesic chemicals to the skin had a subthreshold touch input, became suprathreshold following the injury (Woolf and King, 1990). In keeping with these observations, the present study has shown that following UV-induced inflammation a previously innocuous A-fiber stimulus was able to evoke a response similar to that produced by repeated C-fiber stimulation. These changes in spinal excitability may in part account for the marked mechanical hyperalgesia observed in our behavioral study. In addition spinal excitability changes evoked by A-fiber induced stimulation might relate to one of the features of clinical pain, allodynia, in which stimulation of low-threshold mechanoreceptors evokes the sensation of pain. Prior conditioning of spinal cord circuitry by $\mathrm{C}$-fiber discharges is, however, a prerequisite (LaMotte et al., 1991; Torebjörk et al., 1992; Gracely et al., 1993).

\section{Contribution of NMDA and neurokinin receptor activation to afferent evoked responses}

The characteristics of the VRP observed in the present study were similar to those observed in previous studies (Brugger et al., 1990; Woodley and Kendig, 1991; Thompson et al., 1992, 1993a). Single shock electrical stimulation of the dorsal roots at a strength sufficient to recruit a fast-conducting compound action potential evoked a short-latency early VRP (Fig. 1) followed by short-duration residual polysynaptic activity in both naive and UV-treated preparations. In both preparations the monosynaptic component of the early response was unaffected by either NMDA or neurokinin receptor antagonists and is presumably mediated by activity at the non-NMDA class of excitatory amino acid receptor. This component of the reflex was also unaltered following UV-induced inflammation. Similar 
findings have been reported in vivo, where no changes in the properties of the monosynaptic reflex could be detected following the induction of central sensitization in the rat spinal cord by a brief C-afferent fiber conditioning stimulus (Cook et al., 1986). Presently the residual polysynaptic activity was equally and significantly antagonized by D-AP 5 but not by the neurokinin receptor antagonists in both preparations. This indicated that considerable activation of NMDA receptors occurred even when only A-fibers were stimulated. Although there is some evidence of NMDA receptor activation during monosynaptic EPSPs (Sillar and Roberts, 1988; Ziskind-Conhaim, 1990) and for monosynaptic PSPs (Konnerth et al., 1990), NMDA receptor activation has been shown to participate only in the decay phase of the monosynaptic EPSP evoked in deep dorsal horn neurons following A-fiber stimulation in neonatal rat spinal slices (Gerber and Randic, 1989b). It is most likely, therefore, that the D-AP5-sensitive component represents residual polysynaptic activation of motoneurons.

In both naive and UV-treated preparations the slow (0-2 sec latency) but not the later portion of the prolonged VRP evoked following high-threshold afferent fiber stimulation was significantly depressed by D-AP5. The major portion of the prolonged ventral root response in both naive and UV-treated preparations, however, is resistant to D-AP5. Prolonged D-AP5-resistant synaptic and ventral root potentials have been regularly demonstrated (Thompson et al., 1990, 1992; Woodley and Kendig, 1991) that on the basis of their inhibition by peptide receptor antagonists (mainly spantide) have been attributed to the release of neurokinins from the central terminals of $\mathrm{C}$-afferent fibers (Urban and Randic, 1984; Agaki et al., 1988, Randic et al., 1988). Both SP and NKA are present in the central terminals of C-afferent fibers (Hökfelt et al., 1975; Cuello and Kanazawa, 1978; Ruda et al., 1986) and act preferentially at the NK1 and NK2 receptor sites, respectively (Maggi et al., 1993). Presently we have confirmed our earlier findings (Thompson et al., 1993a) in demonstrating that the selective NK2 receptor antagonist MEN,10376 but not the NK1 receptor antagonists CP-96,345 or RP,67580 significantly reduces the amplitude and area of the prolonged $\mathrm{C}$-fiber evoked VRP in naive animals. Consistent with these findings was the observation that the prolonged excitation of dorsal horn neurons evoked by capsaicin was similarly antagonized by $\mathrm{NK} 2$ but not $\mathrm{NK} 1$ receptor antagonists (Nagy et al., 1992). NK2 receptor antagonists have also been shown to antagonize the responses of dorsal horn neurons in vivo following both brief noxious thermal stimulation (Fleetwood-Walker et al., 1990) and the more prolonged response evoked following the cutaneous application of algogenic substances (Munro et al., 1993). NK1 receptor antagonists were ineffective in these studies. On the other hand, evidence exists for the involvement of the NK 1 receptor in mediating the responses of dorsal horn neurons to acute high-intensity afferent fiber stimulation and cutaneous noxious stimuli (DeKoninck and Henry, 1991; Radhakrishnan and Henry, 1991). However, these studies must be interpreted cautiously because of the potential nonspecific depression by CP-96,345 of L-type calcium channels (Schmidt et al., 1992). The lack of effect of the NK1 receptor antagonists is nevertheless puzzling since both SP and NKA are released into the dorsal horn following high-threshold afferent fiber stimulation (Go and Yaksh, 1987; Duggan et al., 1988 ) and binding sites for both ligands are present in the spinal cord, although these vary greatly in levels and distribution (Charlton and Helke, 1985, 1986; Buck et al., 1986; Yashpal et al., 1990; Takeda and Krause, 1991). The excitatory effects of SP upon dorsal horn neurons are well documented (for review, see Fleetwood-Walker and Mitchell, 1989).

It seems unlikely that the activation of the NK1 receptor depends upon the activation of specific C-afferent fiber inputs, since the electrical stimulation parameters used in the present study would be likely to recruit the majority of fibers within the stimulated dorsal root. NKA is known to be released within the dorsal horn by noxious but not tissue damaging stimuli (Duggan et al., 1990) while SP is relcased by noxious mcchanical stimulation but not by acute noxious thermal stimulation, at least within the functional range of the polymodal C-afferent fibers (Duggan et al., al., 1988; Kuraishi et al., 1989; Tiseo et al., 1990). Measurable release of SP occurred most consistently following thermal stimuli sufficient to evoke acute inflammatory changes (Duggan et al., 1988) or following the induction of joint inflammation (Schaible et al., 1990). In keeping with these observations in the present study, NK1 receptor activation was only observed following a peripheral injury. Recent studies in vivo have also shown that NK1 receptor antagonists do not depress the baseline flexor reflex threshold evoked by stimulation of cutaneous C-afferents but are effective in blocking both the windup evoked following a low-frequency conditioning train as well as the prolonged postconditioning facilitation of the reflex evoked either by SP application or by low-frequency cutaneous C-fiber stimulation (Xu et al., 1992a,b).

Several studies using different inflammatory models have reported elevated levels of neuropeptides in sensory neuron cell bodies and peripheral terminals (Lembeck et al., 1981; Noguchi et al., 1988; Weihe et al., 1988; Donnerer et al., 1992). Indeed, increases in the levels of SP and calcitonin gene-related peptide have been shown in sensory neuron cell bodies following UV irradiation of the rat hind paw (Gillardon et al., 1992). Unilateral peripheral inflammation is also known to induce a selective upregulation of the NK1 receptor in the rat spinal cord (Schäfer et al., 1993). Increased transport and release of SP acting upon an enhanced NK1 receptor complement may contribute to the novel NK1 receptor activation observed in the present study following UV induced injury.

In summary, our present experiments have shown that prolonged C-fiber evoked ventral root responses, which underlie the phenomenon of windup, are not affected by NK 1 receptor antagonists under normal conditions. The enhanced C-fiber evoked response observed following peripheral injury, however, shows a significant NK1 receptor component that is associated with a behavioral hyperalgesia while the NK2 receptor component appears unaltered. Under these conditions, repetitive low-frequency A-fiber stimulation produced a reflex response similar to that evoked by C-fibers in normal animals. These changes are thought to contribute to the phenomenon of central sensitization and relate to the hehavioral hypersensitivity observed in the present experiments.

\section{References}

Akagi H, Konishi S, Otsuka M, Yanagisawa M (1985) The role of substance $\mathrm{P}$ as a neurotransmitter in the reflexes of slow time course in the neonatal rat spinal cord. Br J Pharmacol 84:663-673.

Andreev N, Dray A (1992) Inhibition of nociceptor activity by receptor selective opioids studied in an isolated skin/nerve preparation from hyperalgesic rat. J Physiol (Lond) 542:204P.

Battaglia G, Rustioni A (1988) Cocxistence of glutamate and substance $\mathrm{P}$ in dorsal root ganglion neurons of the rat and monkey. J Comp Neurol 277:302-312. 
Beresford IJM, Birch PJ, Hagan RM, Ircland SJ (1991) Investigation into species variants in tachykinin NK1 receptors by the use of the non-peptide antagonist CP-96,345. Br J Pharmacol 104:292-293.

Bessou P, Perl ER (1969) Response of cutaneous sensory units with unmyelinated fibers to noxious stimuli. J Neurophysiol 32:1025-1043.

Brugger F, Evans RH, Hawkins NS (1990) Effects of $N$-methyl-Daspartate antagonists and spantide on reflexes and responses to substance $\mathrm{P}$ and capsaicin in isolated spinal cord preparations from mouse and rat. Neuroscience 36:611-622

Buck SH, Helke CJ, Burcher E, Shults CW, O'Donohue TL (1986) Pharmacologic characterisation and autoradiographic distribution of binding sites for iodinated tachykinins in the rat central nervous system. Peptides 7:1109-1120.

Calvino B, Villaneva L, LeBars D (1987) Dorsal horn (convergent) neurons in the intact anaesthetized arthritic rat. I. Segmental excitatory influences. Pain 28:81-98.

Campbell JN, Meyer RA, LaMotte RH (1979) Sensitization of myelinated nociceptive afferents that innervate monkey hand. J Neurophysiol 42:1669-1679.

Charlton CG, Helke CJ (1985) Autoradiographic localization and characterization of spinal cord substance P binding sites: high densities in sensory, autonomic, phrenic and Onuf's motor nuclei. J Neurosci 5:1653-1661.

Charlton CG, Helke CJ (1986) Ontogeny of substance P receptors in rat spinal cord: quantitative changes in receptor number and differential expression in specific loci. Dev Brain Res 29:81-91.

Coderre TJ, Melzack R (1992) The contribution of excitatory amino acids to central sensitization and persistent nociception after formalin-induced tissue injury. J Neurosci 12:3665-3670.

Cook AJ, Woolf CJ, Wall PD (1986) Prolonged C-fiber mediated facilitation of the flexion reflex in the rat is not due to changes in afferent terminal or moloneurone excitability. Neurosci Lett 70:9196.

Cook AJ, WoolfCJ, Wall PD, McMahon SB (1987) Dynamic receptive field plasticity in rat spinal dorsal horn following C-primary afferent input. Nature 325:151-153.

Cuello AC, Kanazawa M (1978) The distribution of substance P immunoreactive fibers in the rat CNS. J Comp Neurol 178:129-156.

Davies SN, Lodge D (1987) Evidence for involvement of $N$-methylD-aspartate receptors in windup of class 2 neurons in the dorsal horn of the rat. Brain Res 424:402-406.

DeKoninck Y, Henry JL (1991) Substance P mediated slow excitatory potential elicited in dorsal horn neurons in vivo by noxious stimulation. Proc Natl Acad Sci USA 88:11344-11348.

Dickenson AH, Sullivan AF (1987) Evidence for a role of the NMDA receptor in the frequency dependent potentiation of deep rat dorsal horn nociceptive neurones following $\mathrm{C}$-fibre stimulation. Neuropharmacology 26:1235-1238.

Donnerer J, Schuligoi K, Stein C (1992) Increased content and transport of substance $P$ and calcitonin-gene related peptide in sensory nerves innervating inflamed tissue: evidence for a regulatory function of nerve growth factor in vivo. Neuroscience 49:693-698.

Dougherty PM, Willis WD (1992) Enhanced responses of spinothalamic tract neurons to excitatory amino acids accompany the generation of capsaicin-induced hyperalgesia in the monkey. $J$ Neurosci 12:883-894.

Duggan AW, Hendry IA, Morton CR, Hutchison WD, Zhao ZQ (1988) Cutaneous stimuli releasing immunoreactive substance $P$ in the dorsal horn of the cat. Brain Res 451:261-273.

Duggan AW, Hope PJ, Jarrott B, Schaible H-G, Fleetwood-Walker SM (1990) Release, spread and persistence of immunoreactive neurokinin $\mathrm{A}$ in the dorsal horn of the cat following noxious cutaneous stimulation: studies with antibody microprobes. Neuroscience 35: 195-202.

Evans RH (1986) A slow spinal synaptic response mediated at NMDA receptors. Br J Pharmacol 86:269P.

Fitzgerald M (1985) The postnatal development of cutaneous afferent fibre input and receptive field organization in the rat dorsal horn. $J$ Physiol (Lond) 364:1-18.

Fitzgerald M, Gibson S (1984) The postnatal physiological and neurochemical development of peripheral sensory $\mathrm{C}$-fibres. Neuroscience 13:933-944.

Fitzgerald M, Shaw A, McIntosh N (1987) The postnatal development of the cutaneous flexor reflex: a comparative study in premature infants and newborn rat pups. Dev Med Child Neurol 30:520-526.
Fleetwood-Walker SM, Mitchell R (1989) Role of substance P in nociception. Curr Opin Anaesthesiol 2:645-648.

Fleetwood-Walker SM, Mitchell R, Hope PJ, El-Yassir N, Molony V, Bladon CM (1990) The involvement of neurokinin receptor subtypes in somatosensory processing in the superficial dorsal horn of the cat. Brain Res 519:169-182.

Gerber G, Randic M (1989a) Excitatory amino acid mediated components of synaptically evoked input from dorsal roots to deep dorsal horn neurons in the rat spinal cord slice. Neurosci Lett 106:211-219.

Gerber G, Randic M (1989b) Participation of excitatory amino acid receptors in the slow excitatory synaptic transmission in the rat spinal dorsal horn in vitro. Neurosci Lett 106:220-228.

Gillardon F, Morano I, Zimmermann M (1991) Ultraviolet irradiation of the skin attenuates calcitonin gene-related peptide mRNA expression in rat dorsal root ganglion cells. Neurosci Lett 124:144-147.

Gracely RH, Lynch SA, Bennett GJ (1992) Painful neuropathy: altered central processing maintained dynamically by peripheral input. Pain 51:175-194

Go VLW, Yaksh TL (1987) Release of substance P from the cat spinal cord. J Physiol (Lond) 391:141-167.

Hoheisel U, Mense S (1989) Long term changes in discharge behaviour of cat dorsal horn neurones following noxious stimulation of deep tissues. Pain 36:239-247.

Hökfelt T, Kellerth J-O, Nilsson G, Pernow B (1975) Substance P: localization in the CNS and some primary sensory neurons. Science 190:889-891.

Hylden JLK, Nahin RL, Traub RJ, Dubner R (1989) Expansion of receptive fields of spinal lamina $I$ projection neurons in rats with unilateral adjuvant-induced inflammation: the contribution of dorsal horn mechanisms. Pain 37:229-243.

Kellstein DE, Price DD, Hayes RL, Mayer DJ (1990) Evidence that substance P selectively modulates C-fiber evoked discharges of dorsal horn nociceptive neurons. Brain Res 526:291-298.

Konnerth A, Keller BU, Lev-Tov A (1990) Patch clamp analysis of excitatory synapses in mammalian spinal cord slices. Pfluegers Arch 417:285-290.

Kuraishi Y, Hirota N, Sato Y, Hanashima N, Takagi H, Satoh M (1989) Stimulus specificity of peripherally-evoked substance $\mathrm{P}$ release from the rabbit dorsal horn in situ. Neuroscience 30:241-250.

Laird JM, Cervero F (1989) A comparative study of the changes in receptive field properties of multireceptive and nociceptive rat dorsal horn neurons following noxious mechanical stimulation. J Neurophysiol 62:854-863.

LaMotte RH, Thalhammer JG, Torebjork HE, Robinson CJ (1982) Peripheral neural mechanisms of cutaneous hyperalgesia following mild injury by heat. J Neurosci 2:765-781.

LaMotte RH, Lundberg LER, Torebjörk HE (1992) Pain, hyperalgesia and activity in nociceptive $C$ units in humans after intradermal injection of capsaicin. J Physiol (Lond) 448:749-764.

Lembeck F, Donnerer J, Colpaert FC (1981) Increase of substance P in primary afferent nerves during chronic pain. Neuropeptides 1:175180

Lev-Tov A, Pinco M (1992) In vitro studies of prolonged synaptic depression in the neonatal rat spinal cord. J Physiol (Lond) 447:149169.

Luscher HR, Ruenzel P, Fetz E, Henneman E (1979) Postsynaptic population potentials recorded from ventral roots perfused with isotonic sucrose: connections of group Ia and II spindle afferent fibers with large populations of motoneurons. J Neurophysiol 42:11461164.

Maggi CA, Patacchini R, Rovero P, Giachetti A (1993) Tachykinin receptors and tachykinin receptor antagonists. J Autonom Pharmacol 13:23-93.

McMahcn SB, Wall PD (1984) Receptive fields of rat lamina I projection cells move to incorporate a nearby region of injury. Pain 19: 235-247.

Mendell L (1966) Physiological properties of nonmyelinated fiber projection to the spinal cord. Exp Neurol 16:316-332.

Molander C, Grant G (1986) Laminar distribution and somatotopic organization of primary afferent fibers from hindlimb nerves in the dorsal horn. A study by transganglionic transport of horseradish peroxidase in the rat. Neuroscience 19:297-312.

Munro FE, Fleetwood-Walker SM, Parker RMC, Mitchell R (1993) Mustard-oil evoked activation of rat dorsal horn neurons is inhibited by NK2 but not NK1 receptor antagonists. Br J Pharmacol 108:243P. 
Nagy I, Maggi CA, Dray A, Woolf CJ, Urban L (1992) The role of neurokinin and NMDA receptors in capsaicin-sensitive synaptic transmission in the dorsal horn of the rat spinal cord. Neuroscience 52:1029-1037.

Noguchi K, Morita Y, Kiyama H, Ono K, Tohyama M (1988) A noxious stimulus induces the preprotachykinin-A gene expression in the rat dorsal root ganglion: a quantitative study using in situ hybridisation histochemistry. Mol Brain Res 4:31-35.

Nussbaumer JC, Yanagisawa M, Otsuka M (1989) Pharmacological properties of a $\mathrm{C}$-fibre response evoked by saphenous nerve stimulation in an isolated spinal cord nerve preparation of the newborn rat. Br J Pharmacol 98:373-382.

Ogawa T, Kanazawa I, Kimura S (1985) Regional distribution of substance $P$, neurokinin and neurokinin in rat spinal cord, nerve roots and dorsal root ganglia, and the effects of dorsal root section or spinal transection. Brain Res 359:152-157.

Otsuka M, Konishi M (1974) Electrophysiology of the mammalian spinal cord in vitro. Nature 252:733-734.

Otsuka M, Yanagisawa M (1988) Effect of a tachykinin antagonist on a nociceptive reflex in the isolated spinal cord tail preparation of the newborn rat. J Physiol (Lond) 395:255-270.

Perkins MN, Campbell E, Urban L, Dray A (1993) Hyperalgesia induced by ultraviolet irradiation in the rat: differential sensitivity to morphine and ibuprofen. J Physiol (Lond) 459:205P.

Price DD, Hull CD, Buchwald NA (1971) Intracellular responses of dorsal horn cells to cutaneous and sural nerve $A$ and $C$-fiber stimulation. Exp Neurol 33:291-305.

Radhakrishnan V, Henry JL (1991) Novel substance P antagonist, CP-96,345, blocks responses of cat spinal dorsal horn neurons to noxious cutaneous stimulation and to substance P. Neurosci Lett 132: $39-43$.

Randic M, Jeftinija S, Urban L, Raspantini C, Folkers K (1988) Effects of substance $\mathbf{P}$ analogues on spinal dorsal horn neurons. Peptides 9:651-660.

Ruda MA, Bennett GJ, Dubner R (1986) Neurochemistry and neuronal circuitry in the dorsal horn. In: Progress in brain research, Vol 66, Peptides and neurological diseases (Emson PC, Rosser M, Tokyama M, eds), pp 219-268. Amsterdam: Elsevier.

Schäfer MK-H, Nohr D, Krause JE, Weihe E (1993) Localization of NK1 receptor mRNA in rat spinal cord: selective upregulation in unilateral peripheral inflammation. Neuropeptides 24:P83.

Schaible HG, Schmitdt RF, Willis WD (1987) Enhancement of the responses of ascending tract cells in the cat spinal cord by acute inflammation of the knee joint. Exp Brain Res 66:489-499

Schaible HG, Jarrott B, Hope PJ, Duggan AW (1990) Release of immunoreactive substance $P$ in the spinal cord during development of acute arthritis in the knee joint of the cat: a study with antibody microprobes. Brain Res 529:214-223.

Schmidt AW, McLean S, Heym J (1992) The substance P receptor antagonist CP-96,345 interacts with $\mathrm{Ca}^{2+}$ channels. Eur J Pharmacol 215:351-355.

Schneider SP, Perl ER (1988) Comparison of primary afferent and glutamate excitation of neurons in the mammalian spinal dorsal horn. J Neurosci 8:2062-2073.

Sillar KT, Roberts A (1988) Unmyelinated cutaneous afferent neurons activate two types of excitatory amino acid receptor in the spinal cord of Xenopus laevis embryos. J Neurosci 8:1350-1360.

Simone DA, Baumann TK, Collins JG, LaMotte RH (1989) Sensitization of cat dorsal horn neurons to innocuous mechanical stimulation after intradermal injection of capsaicin. Brain Res 486:185189.

Sivilotti LG, Thompson SWN, Woolf CJ (1993) Rate of rise of the cumulative depolarization evoked by repetitive stimulation of small caliber afferents is a predictor of action potential windup in rat spinal neurons in vitro. J Neurophysiol 69:1621-1632.

Snederor GW, Cochran WG (1978) Statistical methods. Ames, IA: Iowa State University.

Szolcsányi J (1987) Selective responsiveness of polymodal nociceptors of the rabbit ear to capsaicin, bradykinin and ultra-violet irradiation. J Physiol (Lond) 388:9-23.

Takeda Y, Krause JE (1991) Pharmacological and molecular biological studies on the diversity of rat tachykinin NK2 receptor subtypes in rat central nervous system, duodenum, vas deferens and urinary bladder. Ann NY Acad Sci 632:479-482.

Thompson SWN, King AE, Woolf CJ (1990) Activity-dependent changes in rat ventral horn neurones in vitro: summation of prolonged afferent evoked postsynaptic depolarizations produce a D-AP5 sensitive windup. Eur J Neurosci 2:638-649.

Thompson SWN, Gerber G, Sivilotti LG, Woolf CJ (1992) Long duration ventral root potentials in the neonatal rat spinal cord in vitro: the effects of ionotropic and metabotropic excitatory amino acid receptor antagonists. Brain Res 595:87-97.

Thompson SWN, Urban L, Dray A (1993a) Contribution of NK1 and NK2 receptor activation to high threshold afferent fiber evoked ventral root responses in the rat spinal cord in vitro. Brain Res 625:100108.

Thompson SWN, Woolf CJ, Sivilotti LG (1993b) Small-caliber afferent inputs produce a heterosynaptic facilitation of the synaptic responses evoked by primary afferent A-fibers in the neonatal rat spinal cord in vitro. J Neurophysiol 69:2116-2128.

Tiseo PJ, Adler MW, Liu-Chen LY (1990) Differential release of substance $P$ and somatostatin in the rat spinal cord in response to noxious cold and heat; effect of dynorphin $A_{(1-17)}$. J Pharmacol Exp Ther 252: 539-545.

Torebjörk HE, Lundberg LER, LaMotte RH (1992) Central changes in processing of mechanoreceptive input in capsaicin-induced secondary hyperalgesia in humans. J Physiol (Lond) 448:765-780.

Treede R-D, Meyer RA, Raja SN, Campbell JN (1992) Peripheral and central mechanisms of cutaneous hyperalgesia. Prog Neurobiol $38: 397-421$.

Urbạn L, Randic M (1984) Slow excitatory transmission in rat dorsal horn: possible mediation by peptides. Brain Res 290:336-341.

Urban L, Perkins MN, Campbell E, Dray A (1993) Responses of deep dorsal horn neurones in the anaesthetized rat during hyperalgesia of the hindpaw induced by ultra-violet irradiation. Neuroscience 57 : $167-172$.

Wall PD, Woolf CJ (1984) Muscle but not cutaneous C-afferent input produces prolonged increase in excitability of the flexion reflex in the rat. J Physiol (Lond) 356:443-458.

Weihe E, Nohr D, Millan MJ, Stein C, Müller S, Gramsch C, Herz A (1988) Peptide neuroanatomy of adjuvant-induced arthritic inflammation in rat. Agents Actions 25:255-259.

Woodley SJ, Kendig JJ (1991) Substance P and NMDA receptors mediate a slow nociceptive ventral root potential in the neonatal rat spinal cord. Brain Res 559:17-21.

Woolf CJ (1983) Evidence for a central component of postinjury pain hypersensitivity. Nature 308:686-688.

WoolfCJ (1984) Long term alterations in the excitability of the flexion reflex produced by peripheral tissue injury in the chronic decerebrate rat. Pain 18:325-343.

Woolf CJ, King AE (1989) Physiology and morphology of multireceptive neurons with $\mathrm{C}$-afferent fiber inputs in the deep dorsal horn of the rat lumbar spinal cord. J Neurophysiol 58:460-479.

Woolf CJ, King AE (1990) Dynamic alterations in the cutaneous mechanosensitive receptive fields of dorsal horn neurones in the rat spinal cord. J Neurosci 10:2717-2726.

Woolf CJ, McMahon SB (1985) Injury induced plasticity of the flexor reflex in chronic decerebrate rats. Neuroscience 16:395-404.

Woolf CJ, Thompson SWN (1991) The induction and maintenance of central sensitization is dependent upon $N$-methyl-D-aspartatic acid receptor activation; implications for the treatment of post-injury pain hypersensitivity states. Pain 44:293-299.

Woolf CJ, Wall PD (1986) The relative effectiveness of C primary afferent fibers of different origins in evoking a prolonged facilitation of the flexor reflex in the rat. J Neurosci 6:1433-1443.

Xu X-J, Maggi CM, Wiesenfeld-Hallin Z (1991) On the role of NK2 tachykinin receptors in the mediation of spinal reflex excitability in the rat. Neuroscience 44:483-490.

Xu X-J, Dalsgaard C-J, Wiesenfeld-Hallin Z (1992a) Intrathecal CP 96,345 blocks reflex facilitation induced in rats by substance $P$ and C-fiber conditioning stimulation. Eur J Pharmacol 216:337-344.

Xu X-J, Dalsgaard C-J, Wiesenfeld-Hallin Z (1992b) Spinal substance $\mathrm{P}$ and $N$-methyl-D-aspartate receptors are coactivated in the induction of central sensitization of the nociceptor flexor reflex. Neuroscience 51:641-648.

Yanagisawa M, Otsuka M, Konishi S, Akagi H, Folkers K, Rosell SA (1982) Substance.P antagonist inhibits a slow reflex response in the spinal cord of the newborn rat. Acta Physiol Scand 116:109-112.

Yashpal K, Dam TC, Quirion R (1990) Quantitative autoradiographic 
distribution of multiple neurokinin binding sites in rat spinal cord. Brain Res 506:259-266.

Yoshimura M, Jessell TM (1989) Primary afferent evoked synaptic responses and slow potential gencration in rat substantia gelatinosa neurons in vitro. J Neurophysiol 62:96-108.

Yoshimura M, Jessell TM (1990) Amino acid mediated EPSPs at primary afferent synapses with substantia gelatinosa neurons in the rat spinal cord. J Physiol (Lond) 430:315-335.

Ziskind-Conhaim L (1990) NMDA receptors mediate poly- and monosynaptic potentials in motoneurons of rat embryos. J Neurosci 10:125-135. 